\title{
Glutamate motivational ensembles in nucleus accumbens: rostrocaudal shell gradients of fear and feeding
}

\author{
Sheila M. Reynolds and Kent C. Berridge \\ Department of Psychology, University of Michigan, Ann Arbor, MI 48109-1109, USA
}

Keywords: affect, AMPA, aversion, defense, NMDA, rat, reward

\begin{abstract}
This study demonstrates that microinjection of an AMPA/kainate glutamate antagonist elicits motivated fear and feeding behaviour mapped along rostrocaudal gradients of positive-to-negative valence in nucleus accumbens shell (similar to rostrocaudal shell gradients recently reported for GABA agonist microinjections). Rats received rostral or caudal microinjections of the glutamate AMPA/ kainate receptor antagonist DNQX $(0,50,450$ or $850 \mathrm{ng}$ in $0.5 \mu \mathrm{L})$ or the NMDA receptor antagonist MK-801 $(0,0.5,1$ or $2 \mu \mathrm{g}$ in $0.5 \mu \mathrm{L})$, into medial accumbens shell prior to behavioural tests for fear, feeding or conditioning of place preference or avoidance. Another group received rostral or caudal microinjections of DNQX in nucleus accumbens core. Rostral shell DNQX microinjections potently increased appetitive food intake and established only weak conditioned place avoidance. Caudal shell DNQX microinjections elicited defensive treading behaviour, caused rats to defensively bite the experimenter and emit fearful distress vocalizations when handled, and established strong conditioned place avoidance. By contrast, no rostrocaudal gradients of motivational bivalence were produced by microinjections of the glutamate AMPA/kainate receptor antagonist DNQX into the core, or by microinjections of the NMDA antagonist MK-801 into the shell. Our results indicate that appetitive and aversive motivation is carried in anatomically differentiated channels by mesocorticolimbic glutamate signals to microcircuits in the medial shell. Hyperpolarization of local shell ensembles by AMPA/kainate glutamate receptor blockade elicits fear and feeding behaviours mapped along distinct positive-to-negative rostrocaudal gradients.
\end{abstract}

\section{Introduction}

The nucleus accumbens mediates both positive motivation (appetitive behaviour and reward) and negative motivation (aversive behaviour and stress) (Blackburn et al., 1992; Salamone, 1994; Wise, 1998; Berridge et al., 1999; Gray et al., 1999; Kelley, 1999; Koob, 1999; McBride et al., 1999; Horvitz, 2000). An important topic for affective neuroscience is how neural mechanisms within accumbens channel the motivational valence of appetitive vs. aversive states.

Recent findings suggest that accumbens GABAergic microcircuits may map appetitive and aversive channels of information along rostrocaudal gradients in the medial shell. Rostral microinjections of a $\mathrm{GABA}_{\mathrm{A}}$ agonist in the shell elicit appetitive eating behaviour, increase hedonic reactions to sweet tastes, and establish conditioned place preferences (Stratford \& Kelley, 1997; Basso \& Kelley, 1999; Reynolds \& Berridge, 2001, 2002). However, caudal shell muscimol microinjections produce defensive treading behaviour (Reynolds \& Berridge, 2001, 2002), which is a natural species-specific fearful or antipredator response which rodents display towards rattlesnakes and scorpions (Owings \& Coss, 1977; Wilkie et al., 1979; Londei et al., 1998; Owings \& Morton, 1998). Caudal shell GABAergic microinjections also elicit other aversive behaviours such as distress vocalizations, increase bitter-typical 'disliking' reactions to tastes, cause conditioned place avoidances, and suppress food intake (Reynolds \& Berridge, 2001, 2002).

Because the majority of GABA released within the accumbens comes from intrinsic medium spiny neurons projecting onto their neighbours

Correspondence: Dr Sheila M. Reynolds, as above.

E-mail: sheilar@umich.edu

Received 18 January 2003, revised 10 March 2003, accepted 12 March 2003
(Sun \& Cassell, 1993; Churchill \& Kalivas, 1994; Kawaguchi et al., 1995; Van Bockstaele \& Pickel, 1995; Meredith, 1999), effects of GABA agonists there may reveal mainly how intrinsic microcircuits within the accumbens organize appetitive vs. defensive behaviour. Conversely, glutamate afferents convey extrinsic signals to the accumbens about motivational stimuli from prefrontal cortex, amygdala and hippocampus (Beckstead, 1979; Christie et al., 1987; Fuller et al., 1987; Sesack et al., 1989; McDonald, 1991; O’Donnell \& Grace, 1993; Groenewegen et al., 1999; Everitt et al., 2001; Cardinal et al., 2002). Glutamate acts on AMPA, kainate and NMDA receptors in accumbens, though it has been suggested that AMPA receptors are most exclusively postsynaptic in location and play a primary postsynaptic role in mediating amygdala and hippocampal inputs (Pennartz et al., 1990, 1991; 1994; Meredith et al., 1993; O’Donnell \& Grace, 1995; Hu \& White, 1996; Gracy et al., 1997; Tarazi et al., 1998a, b). Examining how glutamate transmission organizes appetitive and defensive behaviour within the accumbens shell may better reveal how the accumbens functions within larger mesocorticolimbic circuitry.

Suppression of glutamate neurotransmission by antagonist administration may hyperpolarize accumbens shell microcircuits similar to a $\mathrm{GABA}_{\mathrm{A}}$ agonist. Reduced glutamate levels in medial accumbens shell have been reported during both spontaneous appetitive eating behaviour and exposure to noxious stimuli (Saulskaya \& Marsden, 1995, 1997; Rada et al., 1997; Saulskaya \& Mikhailova, 2002). In a related effect, AMPA/kainate receptor blockade in shell can specifically stimulate food intake (Maldonado-Irizarry et al., 1995; Kelley \& Swanson, 1997; Stratford et al., 1998).

If mesocorticolimbic glutamate inputs to the accumbens have partially segregated information channels for processing appetitive and aversive motivational signals, similar to GABA inputs, then 
glutamate antagonists may also elicit motivated behaviour of different valence along a similar rostrocaudal gradient as do GABA agonists (Reynolds \& Berridge, 2001, 2002). The present study tested this prediction. We compared eating behaviour and food intake vs. fearful defensive treading behaviour and assessed establishment of conditioned place avoidance after microinjections of DNQX, an AMPA/ kainate glutamate receptor antagonist, into the shell or core and after microinjections of MK-801, an NMDA receptor antagonist, into the shell. We found a rostrocaudal gradient of positive-to-negative motivational valence specifically after AMPA/kainate blockade in the shell.

\section{Materials and methods}

\section{Experiment 1: fear and feeding behaviours elicited after AMPA/kainate or NMDA blockade in shell or core}

In order to minimize the number of microinjections and associated site damage for each rat, Experiment 1 was divided into two comparisons using separate groups. An anatomical comparison group focused on the relative roles of shell vs. core, and a receptor subtype comparison group focused on the relative roles of glutamate AMPA/kainate vs. NMDA receptor subtypes. Because earlier studies and pilot core and shell data implicated the shell primarily for fear and feeding gradients, special emphasis was placed on the shell for the comparison of receptor subtypes.

The anatomical comparison assessed the fear and feeding effects of microinjections in either medial shell (60 rats) or accumbens core (21 rats) of the freshly prepared AMPA/kainate receptor antagonist DNQX (6,7-dinitroquinoxaline-2,3(1H,4H)-dione; Sigma, St Louis, USA; 0, 450 , and $850 \mathrm{ng}$ in $0.5 \mu \mathrm{L} 50 \% \mathrm{DMSO}: 50 \% 0.15 \mathrm{M}$ sterile saline). The receptor subtype comparison assessed dose-response effects of shell microinjections of either the NMDA glutamate receptor antagonist MK-801 (dizocilpine; Sigma; 0, 0.5, 1.0, $2.0 \mu \mathrm{g}$ in $0.5 \mu \mathrm{L} 0.15 \mathrm{M}$ sterile saline; 17 rats) or the AMPA/kainate glutamate receptor antagonist DNQX $(0,50,450$, and $850 \mathrm{ng}$ in $0.5 \mu \mathrm{L} ; 30$ rats $)$. All studies were approved by the VCUCA committee of the University of Michigan in compliance with NIH standards.

\section{Subjects}

Male and female Sprague-Dawley rats (270-320 g at time of surgery) were group-housed $\left(\approx 21^{\circ} \mathrm{C} ; 12\right.$-h light: 12 -h dark cycle) with ad libitum food (Purina rat chow) and water (tap water) available. Male and female data did not differ in initial analysis, and so are combined in results below.

\section{Surgery}

Rats were pretreated with $0.1 \mathrm{~mL}$ of atropine sulphate and anaesthetized with a mixture of ketamine $\mathrm{HCl}$ and xylazine $(80$ and $5 \mathrm{mg} / \mathrm{kg}$, respectively) and placed in a sterotaxic apparatus (David Kopf; Tujunga, CA, USA) with the incisor bar set at $5.0 \mathrm{~mm}$ above interaural zero to avoid penetrating the lateral ventricles. Microinjection placements were staggered at $0.3-\mathrm{mm}$ intervals in the anterior-posterior dimension within each group to cover the entire rostrocaudal extents of core and shell. Within other planes, cannula sites were clustered at 0.1$\mathrm{mm}$ intervals or less along dorsoventral and mediolateral axes.

For both experimental groups, chronic microinjection guide cannulae (23-gauge) were implanted bilaterally $2.0 \mathrm{~mm}$ above accumbens sites either in the medial shell or in the core. Placement coordinates were chosen to fit into the contours of the medial shell or into similar rostrocaudal levels of the core (Figs 1-3). Shell placements were AP $3.4-2.1 \mathrm{~mm}$ anterior to bregma, $\mathrm{ML} \pm 0.8-1.2 \mathrm{~mm}$ lateral to midline and DV 5.5 to $5.8 \mathrm{~mm}$ below the surface of the skull. This resulted in microinjections distributed across several rostrocaudal levels (all measurements anterior to bregma): $\approx 2.2(n=2$ rats), $1.7(n=7)$, $1.6(n=13), 1.2(n=9), 1.0(n=7), 0.7 \quad(n=15)$ and $0.5 \mathrm{~mm}$ $(n=5)$. Core placements were AP $3.4-2.6 \mathrm{~mm}$ anterior to bregma, $\mathrm{ML} \pm 1.4-2.6 \mathrm{~mm}$ lateral to midline, and DV $4.5-5.0 \mathrm{~mm}$ below the surface of the skull. Core microinjections were distributed across several rostrocaudal levels (all measurements anterior to bregma): $\approx 1.7$ ( $n=1$ rat), $1.6(n=6), 1.2(n=4), 1.0(n=4)$ and $0.7 \mathrm{~mm}$ $(n=6)$. Microinjection guide cannulae were anchored to the skull with screws and acrylic cement. A stainless steel obturator was inserted into each guide cannula to help prevent occlusions. Each rat received prophylactic penicillin (aquacillin; $45000 \mathrm{U}$ i.m.) after surgery. At least 7 days were allowed for recovery before the beginning of behavioural testing.

\section{Intracerebral microinjections}

While a rat was gently hand-held or cradled in the experimenter's arm, its bilateral cannulae were attached to a syringe pump via PE-20 tubing, and $0.5-\mu \mathrm{L}$ microinjections were made at a rate of $0.30 \mu \mathrm{L} / \mathrm{min}$ using a stainless steel injector cannula (29-gauge) which extended $2.0 \mathrm{~mm}$ beyond the ventral tip of the cannula guide. Animals received doses of the antagonists or vehicle in counterbalanced order with 48-h rest between microinjection trials. Control microinjections contained only the appropriate vehicle for each drug. After infusions, the microinjectors remained in place for an additional $60 \mathrm{~s}$ to allow for drug diffusion before obturators were replaced, and the animal was placed immediately in the test chamber.

\section{Behavioural eating and defensive treading tests}

Rats had $a d$ lib access to food and water prior to all tests. To assess the motivational valence of microinjection effects, rats were given simultaneous opportunities to express either eating, drinking or defensive treading behaviours as they chose during the 1-h test, and all behaviours were measured as described previously (Reynolds \& Berridge, 2001). Briefly, rats were habituated to test chambers for four consecutive days prior to microinjections and received a vehicle microinjection on the final day of habituation. The transparent test chambers $(23 \times 20 \times 45 \mathrm{~cm})$ contained preweighed food $(\approx 20 \mathrm{~g}$ Purina rat chow pellets), a water spout and wood shavings ( $2 \mathrm{~cm}$ deep) which could be used by a rat for defensive treading behaviour (and piled into mounds, usually positioned between the rat and its perceived threat such as the transparent front wall that revealed the experimenter). The behaviour of each rat was videotaped for later off-line analysis of durations of eating, drinking and defensive treading behaviour. Remaining food pellets were re-weighed after the 60 -min test to measure grams eaten. The bedding and floor of the cage were also inspected for any food crumbs, which were separated and weighed (but this check never revealed more than a minimal dusting of crumbs, i.e. $<0.5 \mathrm{~g}$ ).

\section{Videoscoring of eating and defensive treading}

The videotapes were scored by an experimenter who was blind to drug treatment. Behaviour was analysed for time spent in eating behaviour (scored whenever a rat's mouth touched a food pellet or showed continual rhythmic chewing movements), drinking behaviour (tongue in contact with the water spout) and defensive treading behaviour (alternating movements of both forepaws or of a single forepaw forward and backward, rapidly repeated and emitted in continuous bouts, and which shoved or sprayed wood shavings forward in front of the rat).

\section{Defensive bites, distress calls and other fear behaviours}

Defensive bites, distress calls and related fearful reactions to the experimenter were recorded at the end of each behavioural test session. 
Using standardized movements, the experimenter quietly lifted the cage's lid, slowly reached into the test chamber $(\approx 15 \mathrm{~cm} / \mathrm{s})$ with a latex- or cloth-gloved hand and, approaching from behind the rat, placed the palm of the hand over the rat's back (with fingers placed just below the rat's forearms to support its weight) to gently lift the rat up and slightly forwards out of the testing chamber. Rats sometimes responded defensively to the experimenter's approach and touch with bites, distress vocalizations and/or attempts to flee. These different defensive reactions were noted (each scored as either occurring or not), and the number of each type of reaction was also recorded in the NMDA vs. AMPA/kainate comparison group. A defensive bite was scored if the rat either actually bit the glove or attempted to bite by opening its jaw while suddenly moving its head toward the glove (as the experimenter's hand retreated). A distress vocalization was scored if the rat audibly vocalized within $1 \mathrm{~s}$ of being touched by the experimenter. An escape dash was scored if the rat suddenly dashed at least $20 \mathrm{~cm}$ away from the experimenter's hand or leapt over the chamber wall (>20 cm high). Occasionally, the rat reacted so defensively that it could not be taken out of the test chamber on the first attempt (this happened only after caudal shell DNQX microinjections, as described below). In such cases, that animal was allowed to calm down for 1-30 min, depending on the duration of agitation displayed by the rat, and then another retrieval was attempted.

\section{Histology}

Rats were deeply anaesthetized with sodium pentobarbital after behavioural tests ended, given ink microinjections $(0.5 \mu \mathrm{L})$ to aid anatomical localization of microinjection sites, and perfused transcardially with buffered saline followed by buffered $4 \%$ paraformaldehyde solution. The brains were removed, postfixed, coronally sectioned $(40 \mu \mathrm{m})$, mounted on slides and stained with Cresyl Violet. Cannula placements were mapped onto corresponding coronal, saggital and horizontal atlas drawings of Paxinos \& Watson (1997).

\section{Construction of functional maps}

Criteria were set to plot the relative intensity of motivated behaviours elicited from neuroanatomical microinjection sites onto functional atlas maps (Reynolds \& Berridge, 2001, 2002). For mapping purposes, the most effective DNQX dose was chosen on an individual basis to plot the maximal behaviour evoked from a site (450 or $850 \mathrm{ng}$ ). Symbols that expressed the maximal intensity of drug-elicited fear and feeding behaviours were plotted on digitized stereotaxic atlas maps using criteria below.

\section{Eating behaviour}

Intake criteria of $>800,>400,>200,>100$ and $<100 \%$ (percentage increase in food intake after DNQX compared to vehicle) were used as the symbol levels to map maximal elicited eating behaviour at each site.

\section{Defensive treading behaviour}

Defensive treading criteria of $>300,>200,>100,>50$ and $<50 \mathrm{~s}$ (time in seconds spent treading after DNQX minus time spent treading after vehicle) were used as symbol levels to map maximal defensive behaviour at each site.

\section{Distress calls, bite attempts and related fear behaviours}

Defensive bites, escape dashes and distress vocalizations elicited when the experimenter tried to pick up a rat at the end of a trial were mapped to reflect combined intensity. Bites appeared to be the most intense defensive reaction in the sense of having the highest threshold: bites occurred only in combination with distress vocalizations and escape dashes, whereas distress vocalizations or escape dashes could occur alone or together without bites. Incidence scores for each site were plotted using the criteria of triple combination of bite plus vocalization plus escape dash; double combination of vocalization plus dash; and single occurrence of either vocalization or dash.

\section{Statistical analysis}

Effects of each behaviour at rostrocaudal levels of shell or core were examined by one-factor (drug) repeated-measures or two-factor mixed within- or between-subjects ANOVA (drug $\times$ anatomical levels of 2.2, 1.7, 1.6, 1.2, 1.0, 0.7 and $0.5 \mathrm{~mm}$ anterior to bregma). When significant main effects were found, additional statistical analysis was performed with one-way ANOVA and post hoc comparisons with the Bonferroni test. Analysis of frequencies of distress vocalizations and biting behaviour were performed with $\chi^{2}$ and $z$-tests of proportions. Correlations were analysed with the Pearson Product Moment test.

\section{Experiment 2: conditioned place preference or avoidance established by rostral vs. caudal shell glutamate blockade}

If a true motivational gradient exists for glutamatergic hyperpolarization of rostrocaudal microcircuits then a gradient should also be reflected in other types of motivated behaviour besides feeding and fear. Experiment 2 asked whether glutamate antagonist microinjections that produced a rostrocaudal gradient of feeding and fear in Experiment 1 would establish a rostrocaudal gradient of conditioned place preference or avoidance. The AMPA/kainate antagonist DNQX (450 ng) was chosen as the most effective drug and dose at producing a rostrocaudal feeding and fear gradient based on the results of Experiment 1 .

\section{Surgery}

Twenty-eight male and female Sprague-Dawley rats were implanted with bilateral chronic indwelling cannulae in medial accumbens shell as in experiment 1 (rostral shell $n=14,2.2-1.2 \mathrm{~mm}$; caudal shell $n=14,1.1-0.5 \mathrm{~mm}$ anterior to bregma).

\section{Place conditioning training procedure}

Conditioned place preference or avoidance was assessed via an unbiased preference conditioning procedure (Tzschentke, 1998). We used a three-compartment apparatus, containing two large side chambers and a smaller central compartment $(28 \times 21 \times 21$-cm sides, $12 \times 21 \times$ 21-cm centre; Reynolds \& Berridge, 2002). The side compartments differed in wall colouring, floor texture and illumination levels. Initial tests prior to conditioning confirmed that rats did not show significant biases for either of the side chambers $\left(n=8 ; F_{1,15}=3.65 ; P=0.10\right)$ (Tzschentke, 1998), and a separate group of rats were used to confirm that our conditioning procedures were effective at establishing preference for a place if paired with systemic diazepam $(1 \mathrm{mg} / \mathrm{kg}$, i.p.; $n=6, F_{1,11}=5.98, P<0.05$ ) (Spyraki et al., 1985).

Each rat was randomly assigned to have one side compartment paired with DNQX microinjection, and place assignments were counterbalanced across rats. To establish a conditioned place preference or avoidance, rats received four consecutive daily conditioning trials. On two trials, DNQX ( $450 \mathrm{ng}$ in $0.5 \mu \mathrm{L}$; days 2 and 4 ) was paired with the assigned drug compartment for $10 \mathrm{~min}$ after microinjection, and on the other two trials vehicle was paired with the control compartment (days 1 and 3$)$.

\section{Conditioned place preference or avoidance test}

On the test day (day 5), rats were not given microinjections but were simply placed into the central compartment and allowed to freely explore the entire apparatus for $10 \mathrm{~min}$ during which they were 
A.

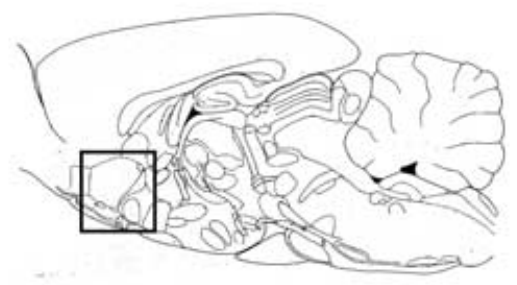

B.
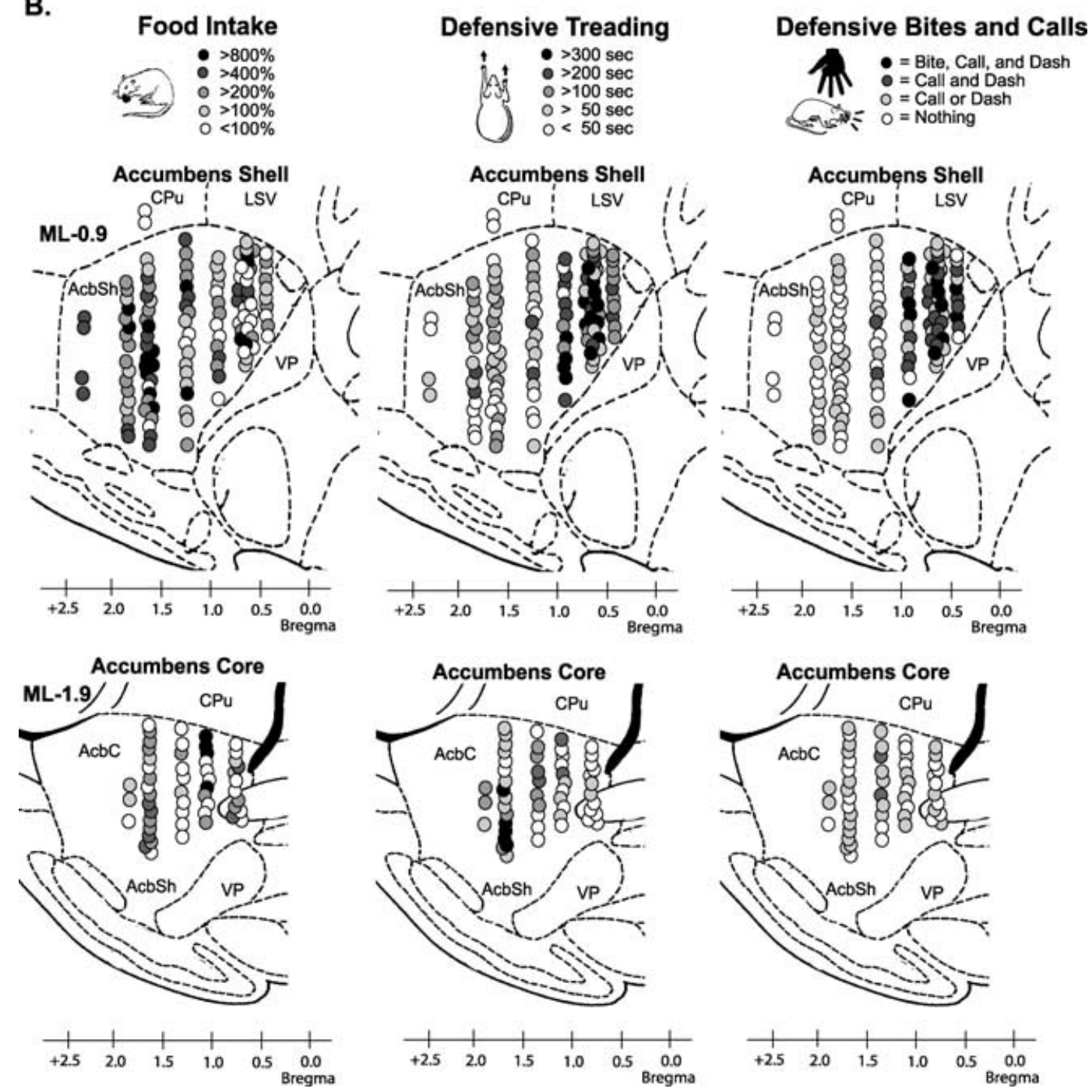

FIG. 1. Saggital function maps of DNQX-elicited food intake and defensive treading behaviour (emitted during the 1-h test), and fearful defensive bites, vocalizations and escape dashes (elicited when the rat was retrieved after testing) for accumbens medial shell ( $0.9 \mathrm{~mm}$ lateral to midline) and core (1.9 mm lateral to midline; all cannula placements are plotted bilaterally, two sites for each rat). Rostrocaudal gradients for motivational valence and behavioural intensity were found for all behaviours. Food intake (left) was elicited most consistently and robustly from rostral shell regions, especially at $1.6 \mathrm{~mm}$ anterior to bregma. Defensive treading behaviour (middle) and distress calls, bites and related behaviour (right) were produced best from caudal shell regions, especially at $0.7 \mathrm{~mm}$ anterior to bregma. Core DNQX microinjections did not produce a rostrocaudal positive-to-negative gradient, although some rostral core injections sites also produced mild defensive treading. Stereotaxic atlas, Paxinos \& Watson (1997).

videotaped. Locations during test sessions were subsequently scored for cumulative seconds spent in each compartment (a rat was considered to be in a particular compartment whenever its head and both forelimbs were across the threshold).

\section{Functional maps of conditioned place avoidance}

To map place preference or avoidance, each rat's place score (measured in absolute seconds) was transformed into a percentage score by dividing the time it spent in its DNQX-paired chamber by the mean time all rats spent in that same chamber across all treatments. The result was expressed as a percentage score, which could be either positive (conditioned place preference) or negative (conditioned place avoidance). Place preference or avoidance percentage scores for each rat's sites were mapped onto a stereotaxic atlas using the criteria: $>10 \%$ increase in place preference for the DNQX-paired place (compared to vehicle microinjection at the same site), no change in 
place preference or avoidance ( $<9 \%$ change), $>10$ or $>25 \%$ increase in place avoidance.

\section{Statistical analysis}

Effects of DNQX microinjections on conditioned place preference were analysed by comparing durations (s) spent in each chamber using 2-way ANOVA (drug $\times$ anatomical site), and significant drug effects were further examined with Bonferroni post hoc tests.

\section{Results}

\section{Experiment 1: AMPA/kainate blockade in shell (but not core) elicited rostrocaudal gradient of eating and defensive treading behaviours}

\section{Shell-evoked eating behaviour: rostral advantage}

Clear and opposite rostrocaudal gradients were found in the shell for DNQX-elicited fear and feeding behaviours (Figs 1 and 2). Food intake was increased most consistently and potently from rostral shell between 2.2 and $1.2 \mathrm{~mm}$ anterior to bregma, and the best sites were rostral to $1.5 \mathrm{~mm}$ (a level where the corpus callosum merges bilaterally and where the tenia tecta ends). In these rostral shell regions, DNQX at least doubled food intake in all rats except two (which were both still increased $93 \%$ above vehicle). Caudally in the shell $(1.1-0.5 \mathrm{~mm}$ anterior to bregma), food intake was less consistently enhanced, and at least half of caudal shell sites failed to double food intake above vehicle levels.

Statistically, DNQX microinjections into the rostral half of the accumbens shell elicited significantly more food intake than sites in the caudal half of the shell (ANOVA for site $\times$ drug interaction, $F_{12,173}=2.02, P<0.05$; Figs $\left.1-4\right)$. Rats ate $300-400 \%$ more food pellets after DNQX than after vehicle at all rostral sites between 2.0 and $1.2 \mathrm{~mm}$ anterior to bregma (rostral $\approx 60 \%$ of shell; overall rostral shell $\left.F_{2,89}=43.42, \quad P<0.001\right), \quad 1.7 \mathrm{~mm}$ anterior to bregma
$\left(F_{2,20}=21.84, P<0.001\right), 1.6 \mathrm{~mm}\left(F_{2,38}=17.511, P<0.001\right)$ and $1.2 \mathrm{~mm}\left(F_{2,26}=11.86, P<0.001\right)$. Caudal shell sites caused less eating after DNQX, though still significantly elevated food intake to $50-150 \%$ above vehicle levels ( 1.0 and $0.7 \mathrm{~mm}$ anterior to bregma, $P<0.05$ each, but no significant increase at $+0.5 \mathrm{~mm}$ ).

The largest increase in food intake was at $\approx 1.6 \mathrm{~mm}$ anterior to bregma in the rostral shell, where the 850-ng DNQX dose caused a $3.9 \pm 0.49 \mathrm{~g}$ increase over vehicle in food intake, which was $>5 \times$ higher than that produced by the same dose more caudally at $\approx 0.7 \mathrm{~mm}$ $(0.6 \pm 0.48 \mathrm{~g}$ increase, $P<0.001 ;$ Fig. 4$)$. In addition, increased intake (DNQX - vehicle intake) was positively correlated with degree of rostral placement in shell at both DNQX doses (450 ng, $r=0.34$, $P<0.01 ; 850 \mathrm{ng}, r=0.41, P<0.001)$. Drinking was typically low, and amount of water drunk was not altered by accumbens shell DNQX microinjections at any level.

\section{Core-evoked eating behaviour: little to no gradient}

DNQX microinjections into the accumbens core hardly increased food intake, causing rats to eat food pellets only $50 \%$ above vehicle level on average (ANOVA for dose, $F_{2,59}=5.62, P<0.01$ ). There was no rostrocaudal gradient in food intake after core DNQX microinjections (ANOVA for site $\times$ dose interaction, $F_{6,59}=1.86$, not significant; Figs 1-3 and 5). In fact, post hoc tests revealed that DNQX only increased food intake at the 450-ng dose $\left(F_{2,17}=16.31\right.$, $P<0.05)$ and further only at one rostrocaudal level $(\approx 1.6 \mathrm{~mm})$. The higher DNQX dose, 850-ng, produced no effect on food intake at any level. Drinking behaviour was never altered after core DNQX microinjections.

\section{DNQX-evoked defensive behaviour: caudal shell advantage}

DNQX in the shell produced a caudally weighted gradient for defensive treading and other fearful behaviours (Figs 1 and 2). Defensive treading was maximal after DNQX between 1.1 and $0.5 \mathrm{~mm}$ anterior to bregma, and especially at $0.7-\mathrm{mm}$ sites (a level where the nucleus of

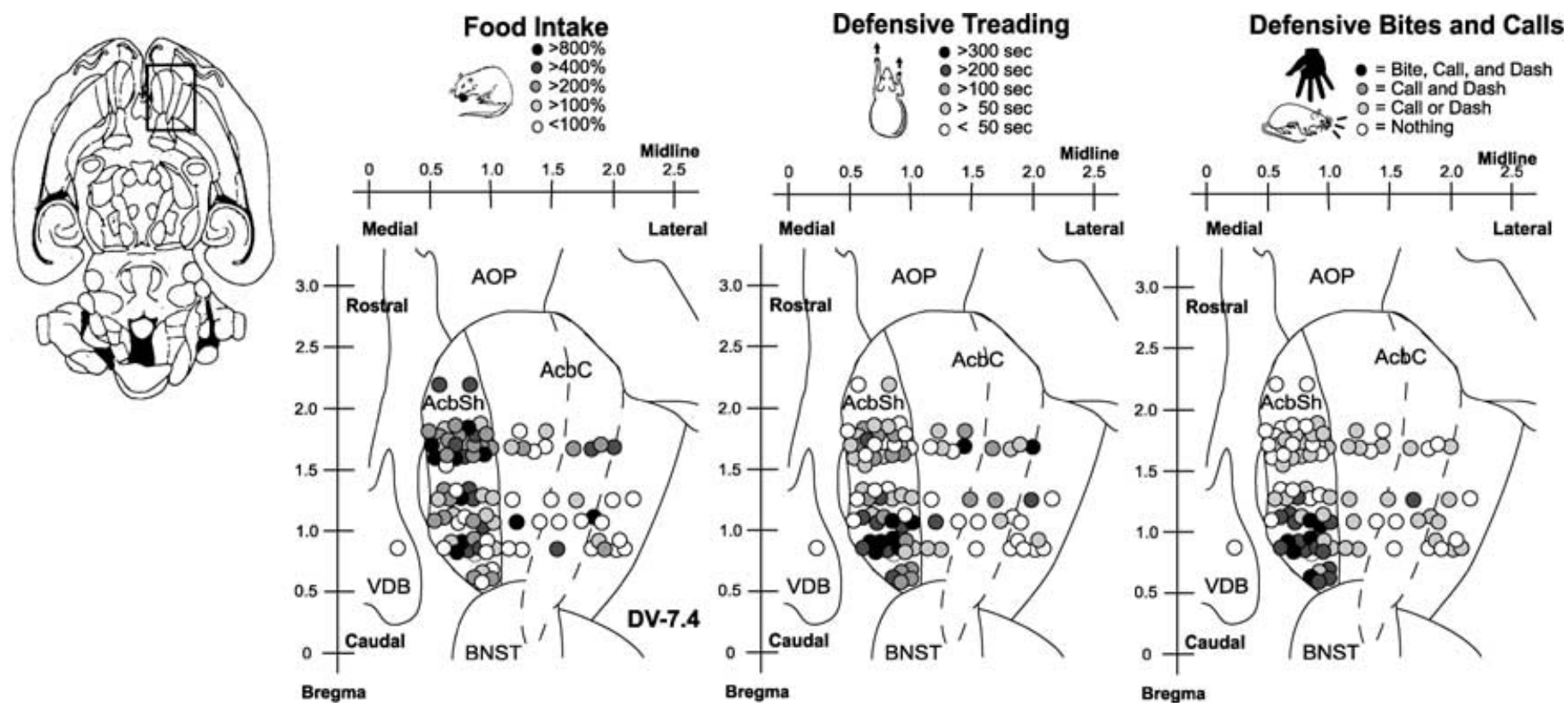

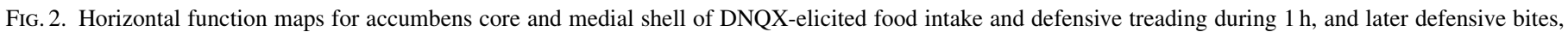

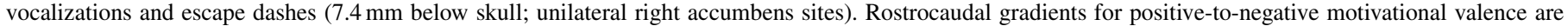
pronounced in shell, but not core. Stereotaxic atlas, Paxinos \& Watson (1997). 

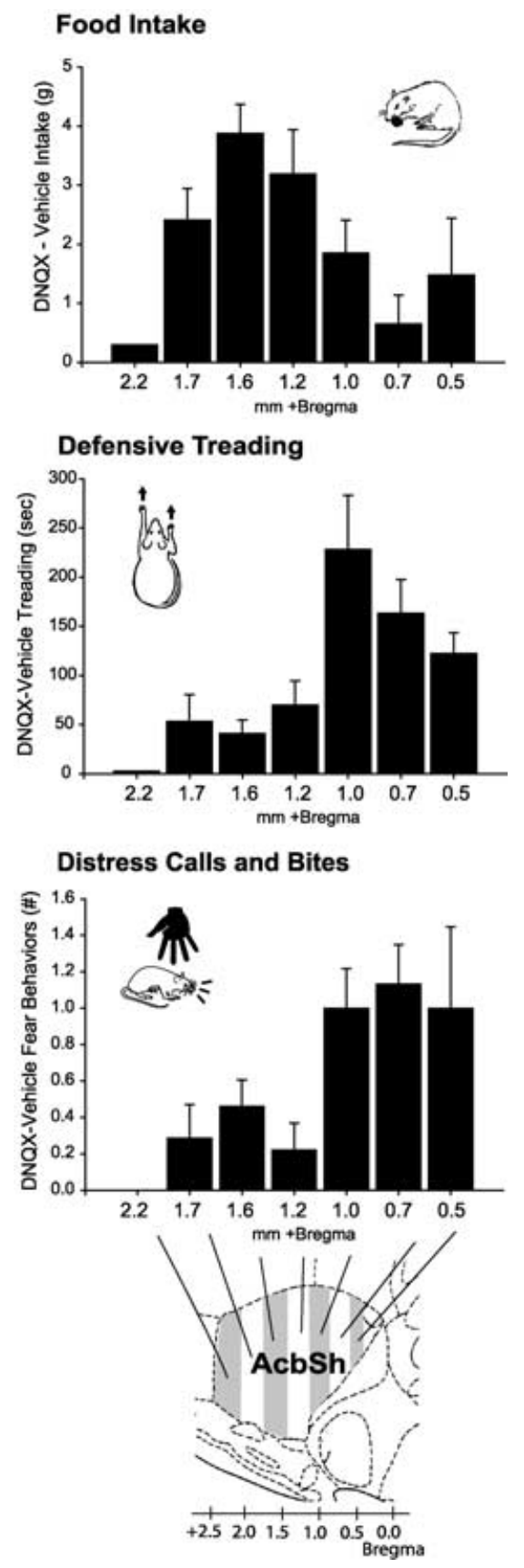

FIG. 3. Food intake and defensive treading behaviour during the $1 \mathrm{~h}$-test, and later defensive bites, vocalizations and escape dashes elicited by microinjections of $850 \mathrm{ng}$ DNQX into accumbens shell (behaviour expressed as individual DNQX - vehicle scores; mean \pm SEM). (Top) Rostral shell DNQX microinjections produced the greatest amount of food intake. (Middle) Caudal shell DNQX injections produced the greatest defensive treading behaviour. (Bottom) Caudal DNQX injections produced greatest defensive bites, vocalizations and escape dash behaviours.

the horizontal limb diagonal band and lambdoid septal areas begin, and where the medial septal nuclei and nuclei of the vertical limb diagonal bands merge). Nearly all caudal shell sites produced at least $50 \mathrm{~s}$ of treading behaviour after DNQX and most caudal sites elicited at least $200 \mathrm{~s}$ of cumulative defensive treading behaviour (whereas vehicle microinjections elicited virtually none). Rostral shell sites usually elicited only small amounts of defensive treading and sometimes none. Over $25 \%$ of rostral sites elicited no defensive treading behaviour at all, and only one rostral shell rat out of 21 showed $>200 \mathrm{~s}$ of treading.

Quantitative behavioural comparisons confirmed that microinjections of DNQX at caudal sites elicited stronger defensive treading behaviour than at rostral sites (ANOVA for site $\times$ drug interaction, $F_{12,173}=2.70, P<0.01$; Figs $1-5$ ). Caudal shell DNQX microinjections robustly elicited up to 4 min cumulative defensive treading behaviour above vehicle levels at sites $1.0 \mathrm{~mm} \quad\left(F_{2,20}=6.24\right.$, $P<0.02), 0.7 \mathrm{~mm}\left(F_{2,44}=14.73, P<0.001\right)$, and $0.5 \mathrm{~mm}$ anterior to bregma $\left(F_{2,14}=10.12, P<0.01\right)$. Conversely, rostral shell DNQX injections at the same doses elicited only $1 \mathrm{~min}$ defensive treading at sites $2.2 \mathrm{~mm}$ (not significant), $1.7 \mathrm{~mm} \quad\left(F_{2,20}=3.50, P=0.064\right)$, $1.6 \mathrm{~mm}\left(F_{2,38}=7.08, P<0.01\right)$ and $1.2 \mathrm{~mm}$ anterior to bregma $\left(F_{2,26}=6.56, P<0.01\right)$. The highest dose at caudal sites interacted to produce the greatest amounts of defensive treading behaviour (twoway ANOVA for dose $\times$ site interaction, $F_{4,167}=4.93, P=0.001$; Fig. 4). A correlation analysis of the relationship between rostrocaudal site and duration of defensive treading behaviour confirmed that the glutamatergic enhancement of defensive treading behaviour (DNQX - vehicle) increased progressively as shell sites became more caudal (significant at both doses: $450 \mathrm{ng}, r=0.37, P<0.005 ; 850 \mathrm{ng}$, $r=0.45, P<0.001)$.

\section{Core-evoked defensive treading: weak reverse gradient}

DNQX microinjections into accumbens core elicited moderate defensive treading behaviour (ANOvA for dose $F_{2,59}=10.21, P<0.001$ ) up to $2 \mathrm{~min}$ at the $850 \mathrm{ng}$ dose, but only from rostral core sites at $1.2 \mathrm{~mm}$ anterior to bregma $\left(F_{2,11}=6.43, P<0.05\right.$; Figs $\left.1-4\right)$ Inspection of the data suggested rostral core might support slightly more DNQXevoked defensive treading than caudal core (the opposite of the shell gradient), but this was a very weak trend and was not statistically significant (ANOVA for dose $\times$ site interaction) $F_{2,59}=1.53$, not significant).

Shell-evoked fearful distress calls and bites: strong caudal shell fear gradient

Over $90 \%$ of caudal shell DNQX sites produced defensive bites or attempts to bite the experimenter's hand at the end of the behavioural test, distress vocalizations and/or escape dashes. Only $\approx 50 \%$ of rostral sites produced any of these, and virtually no rostral sites produced defensive bites or bite attempts. Quantitative analysis confirmed that distress calls, dashes and bites elicited at the end of the test session were evoked by shell DNQX microinjections (compared to vehicle; ANOVA for dose $\left.F_{2,67}=19.03, P<0.001\right)$ and most potently at caudal shell sites (ANOVA for site $F_{5,173}=4.20, P<0.01$; Figs $1-4$ ). Many rats which received DNQX microinjections at caudal shell sites between 1.0 and $0.5 \mathrm{~mm}$ anterior to bregma displayed all three fearful behaviours: (i) distress calls, (ii) escape dashes or successful leaps out of test chamber and (iii) bites $(P<0.05$ each level). At rostral sites, DNQX evoked only one fear behaviour at a time (either distress calls or escape dashes), from only a few rats, and only at $1.6 \mathrm{~mm}$ anterior to bregma $(P<0.05$; not at $2.2,1.7$ or $1.2 \mathrm{~mm})$. A correlation analysis between these fearful behaviours and rostrocaudal site placement confirmed that DNQX elicitation of defensive bites, distress calls and escape dashes was correlated with caudal placement: the more caudal the site, the greater the combined defensive reaction and greater the likelihood of bites $(r=0.46, P<0.001)$.

\section{Core-evoked distress calls and bites: missing and no gradient}

For accumbens core sites, by contrast, little to no defensive bites, distress vocalizations or escape attempts occurred when rats were retrieved after DNQX microinjections (ANOVA for dose $F_{2,59}=2.82$, 
A. Accumbens Shell
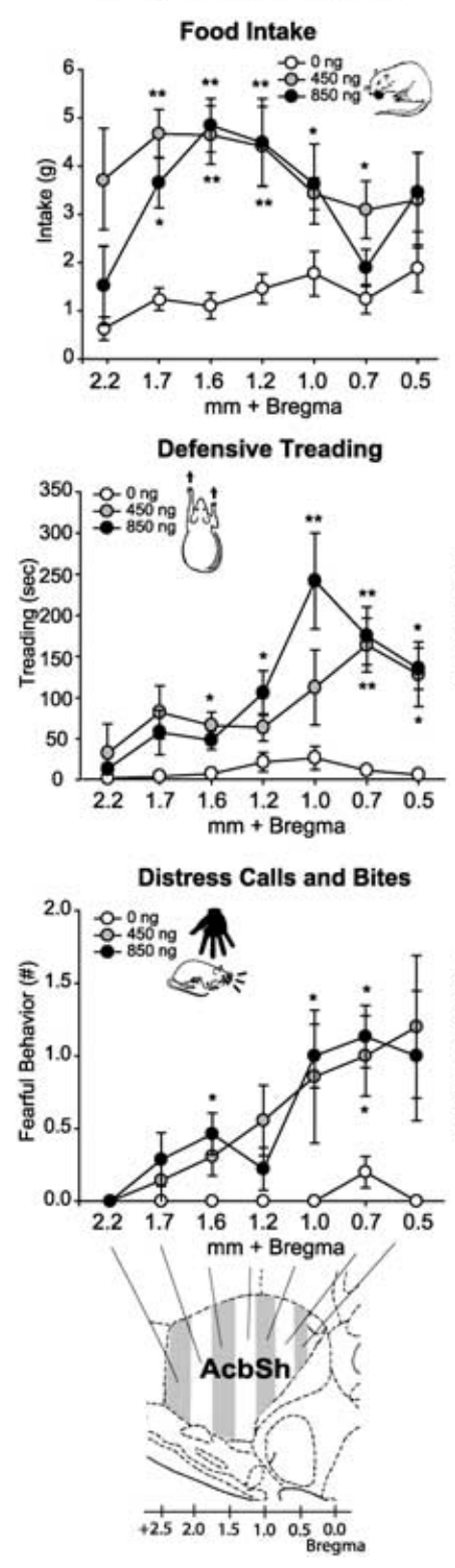

FIg. 4. Food intake and defensive treading behaviour during the 1-h test, and later defensive bites, vocalizations and escape dashes elicited by DNQX microinjections into accumbens shell and core. (A) Shell DNQX injections into rostral regions elicited greatest food intake, but into caudal shell regions elicited greatest defensive treading and bites, distress calls and escapes. (B) Core DNQX microinjections in rostral regions only slightly enhanced defensive treading behaviour, and did not markedly alter food intake or bites, calls and escapes. ${ }^{*} P<0.05,{ }^{* *} P<0.001$ vs. vehicle.

$P=0.074$ ), nor was there any rostrocaudal gradient (ANOVA for dose $\times$ site interaction $F_{6,59}=0.50, P=0.81$; Figs 1,2 and 4).

Essentially no rostrocaudal gradient for eating or fear behaviour was found in the core when behavioural effects of accumbens core DNQX microinjections were anatomically mapped (Figs 1 and 2). Few core sites elicited eating, and those few which did were not segregated rostrocaudally. The mapping of defensive treading sites confirmed, if anything, a weak and reversed rostrocaudal gradient, with the few effective sites concentrated rostrally in accumbens core
(1.7-1.2 $\mathrm{mm}$ anterior to bregma). The occasional defensive treading behaviour elicited at rostral core sites seems not likely to be due to diffusion of DNQX to the shell because these sites were closest to the rostral core which was relatively ineffective for eliciting treading, whereas caudal core sites which were ineffective were closest to caudal shell sites which produced the strongest defensive treading behaviour.

\section{Overlap between appetitive and defensive shell sites}

Many shell microinjection sites elicited both appetitive eating and defensive treading behaviour from the same rat successively during the same hour. Eating behaviour typically occurred first, and was followed by a shift to defensive treading behaviour after 20-30 min. The relative intensities of fear and feeding behaviour conformed to the rostrocaudal gradients described above, but a considerable range of intermediate shell supported both fear and feeding behaviours. Approximately $40 \%$ of shell sites elicited at least some of both appetitive and defensive behaviours which exceeded mapping thresholds. However, strong behavioural extremes tended to be restricted to rostral or caudal ends of the shell. Sites of overlap between appetitive and defensive behaviours appeared to be evenly distributed throughout the shell between the rostrocaudal ends. When relative intensities of simultaneous fear and feeding behaviours were compared, a negative correlation was found between appetitive eating and defensive treading behaviour (450 ng, $r=-0.32, P<0.02 ; 850 \mathrm{ng}, r=-0.21$, $P<0.03$ ), consistent with the rostrocaudal gradients described above. However, the joint appearance of both fear and feeding reactions after most middle shell DNQX microinjections led us to further examine their relative time course in the receptor subtype comparison below.

NMDA vs. AMPA/kainate receptor comparison: only DNQX (not MK 801) in shell elicited fear and feeding behaviours

For comparison of NMDA vs. AMPA/kainate receptor subtypes in eliciting fear and feeding behaviours from accumbens shell, we expanded the dose range to three doses of each antagonist plus vehicle (DNQX, 0, 50, 450 and $850 \mathrm{ng}$; MK-801, 0, 0.5, 1 and $2 \mu \mathrm{g}$ ). In addition, we assessed more sensitively the relative intensities of fear and feeding reactions during different time points within the 1 -h test session, and further quantified the number of defensive bites, distress vocalizations and escape dashes elicited when the experimenter retrieved a rat at the end of the session.

\section{Eating behaviour: shell MK-801 decreased food intake and lacked gradient}

Microinjections of MK-801 never increased food intake, at either rostral or caudal sites in the accumbens shell. Instead, shell MK-801 at the highest dose $(2 \mu \mathrm{g})$ significantly decreased eating behaviour (twoway ANOVA for drug $F_{3,65}=3.64, P<0.05$; Table 1 ) at both rostral and caudal shell sites ( site $F_{1,43}=2.65, P=0.12$ ). Only the highest dose $(2 \mu \mathrm{g})$ of MK-801 suppressed food intake $\left(F_{3,34}=3.77, P<0.05\right)$, whereas 1 - and $0.5-\mu \mathrm{g}$ doses had no significant effects.

By contrast, DNQX microinjections again increased food intake $\left(F_{3,106}=29.68, P<0.001\right)$, and rostral shell DNQX caused the greatest food intake $(>500 \%$ increase), while caudal shell caused a lesser increase $\left(\approx 300 \%\right.$ increase; site $\left.F_{1,106}=6.28, P=0.02\right)$. The two highest doses, 450 and $850 \mathrm{ng}$, each increased eating more than the lowest dose $\left(F_{3,47}=17.07, P<0.001\right)$. The time course of eating behaviour showed an immediate and early effect of DNQX in the shell. Rostral shell DNQX increased time spent eating during the first 5-min bin of the 1-h session ( $\min 0-5, F_{3,47}=5.45, P<0.005$ ), and for every subsequent bin up to $20 \mathrm{~min}(\min 5-20, P<0.01$ each), but not 
TABLE 1. Behaviour elicited by microinjections of MK-801 and DNQX at rostral or caudal sites in the accumbens shell

\begin{tabular}{clllll}
\hline & \multicolumn{2}{l}{ Food intake $(\mathrm{g})$} & & \multicolumn{2}{l}{ Defensive treading $(\mathrm{s})$} \\
\cline { 5 - 6 } Drug & Rostral sites & Caudal sites & & Rostral sites & Caudal sites \\
\hline MK-801 & & & & \\
$0 \mu \mathrm{g}$ & $0.54 \pm 0.21$ & $1.29 \pm 0.33$ & & $18.4 \pm 3.6$ & $9.9 \pm 3.1$ \\
$0.5 \mu \mathrm{g}$ & $0.44 \pm 0.17$ & $0.62 \pm 0.35$ & & $51.9 \pm 9.9$ & $71.6 \pm 12.6^{*}$ \\
$1.0 \mu \mathrm{g}$ & $0.30 \pm 0.12$ & $0.62 \pm 0.20$ & & $62.1 \pm 14.4^{*}$ & $84.6 \pm 16.1^{*}$ \\
$2.0 \mu \mathrm{g}$ & $0.25 \pm 0.16$ & $0.44 \pm 0.19^{*}$ & & $58.1 \pm 7.3^{*}$ & $63.7 \pm 14.2^{*}$ \\
DNQX & & & & \\
$0 \mathrm{ng}$ & $1.24 \pm 0.32$ & $1.11 \pm 0.32$ & & $8.3 \pm 4.9$ & $11.4 \pm 3.7$ \\
$50 \mathrm{ng}$ & $2.53 \pm 0.49$ & $2.87 \pm 0.52^{*}$ & & $45.0 \pm 10.3$ & $68.4 \pm 22.5$ \\
$450 \mathrm{ng}$ & $5.50 \pm 0.39^{* *}$ & $3.49 \pm 0.44^{*}$ & & $82.3 \pm 21.4^{*}$ & $147.3 \pm 29.1^{* *}$ \\
$850 \mathrm{ng}$ & $4.06 \pm 0.65^{* *}$ & $2.69 \pm 0.51^{*}$ & & $54.9 \pm 17.5$ & $220.9 \pm 34.5^{* *}$ \\
\hline
\end{tabular}

${ }^{*} P<0.05,{ }^{* *} P<0.001$, compared with zero doses.

for later bins (min 21-60). Caudal shell DNQX increased eating only in the first three 5-min bins (15 min after injection each $P<0.02)$, but not during any later time bins in the hour (Fig. 5).

\section{Defensive treading: shell MK-801 caused mild defensive treading without gradient}

MK-801 microinjections caused mild defensive treading behaviour at all shell sites $\left(F_{3,64}=11.66, P<0.001\right.$; Table 1$)$. All doses of MK-801 elicited between 50 and $80 \mathrm{~s}$ cumulative treading behaviour regardless of site or dose (rostral, $F_{3,30}=5.24, P<0.01$; caudal, $F_{3,33}=7.09$, $P<0.01$; site, $F_{1,64}=1.47, P=0.24$ ). The mild defensive treading elicited by MK-801 began by $5 \mathrm{~min}$ after microinjection and continued steadily to $60 \mathrm{~min}(P<0.05$ for 10 of 12 bins).

By contrast, DNQX microinjections again elicited strong defensive treading behaviour along a rostrocaudal gradient $\left(F_{1,106}=17.66\right.$, $P<0.001)$, with a significant advantage for caudal microinjections over rostral microinjections $\left(F_{1,106}=9.28, P=0.005\right)$. In the caudal shell, DNQX elicited more defensive treading than did MK-801 at the same sites (ANOVA for drug $F_{1,167}=4.92, P<0.03$ ). The doseresponse effect for DNQX was roughly linear in caudal shell $\left(F_{3,54}=16.01, P<0.001\right)$ and the highest dose of DNQX elicited more treading $(>200 \mathrm{~s}$ cumulative) than the lowest dose $(\approx 70 \mathrm{~s}$; $P<0.001)$. Rostral DNQX elicited mild defensive treading behaviour (50-80 s; $\left.F_{3,47}=4.83, P<0.01\right)$, but this reached significance only for the middle dose $(450 \mathrm{ng} ; P<0.01)$. DNQX-elicited defensive treading behaviour was delayed and late, by contrast to its immediate and early effects on eating behaviour (Fig. 5). No defensive treading enhancement was detectable in the first $10 \mathrm{~min}$ of the test. DNQX-elicited defensive treading from the caudal shell began $10 \mathrm{~min}$ after microinjection ( $\left.\min 10-15, F_{3,54}=4.76, P<0.01\right)$ and lasted until the end of the 60-min test ( $\min 15-60$, each 5 -min bin $P<0.01$ ). After rostral shell microinjections, defensive treading was even more delayed, not becoming evident until $30 \mathrm{~min}$ into the test $\left(\min 30-35, F_{3,47}=7.27\right.$, $P<0.001$ ), when it then remained elevated over vehicle for the rest of the test (min 35-60, each 5-min bin $P<0.05$ ).

\section{Defensive bites and distress calls: no MK-801 fear behaviour or gradient}

MK-801 never caused defensive bites, distress vocalizations or escape dashes when the experimenter picked up the rat at the end of the test (ANOVA for dose $F_{1,64}=0.45, P=0.70$ ). However, DNQX microinjections again greatly increased all of these fear behaviours $\left(F_{1,106}=9.53\right.$, $P<0.001)$. Caudal DNQX sites produced greater increases in defensive bites, vocalizations and dashes than did rostral shell sites
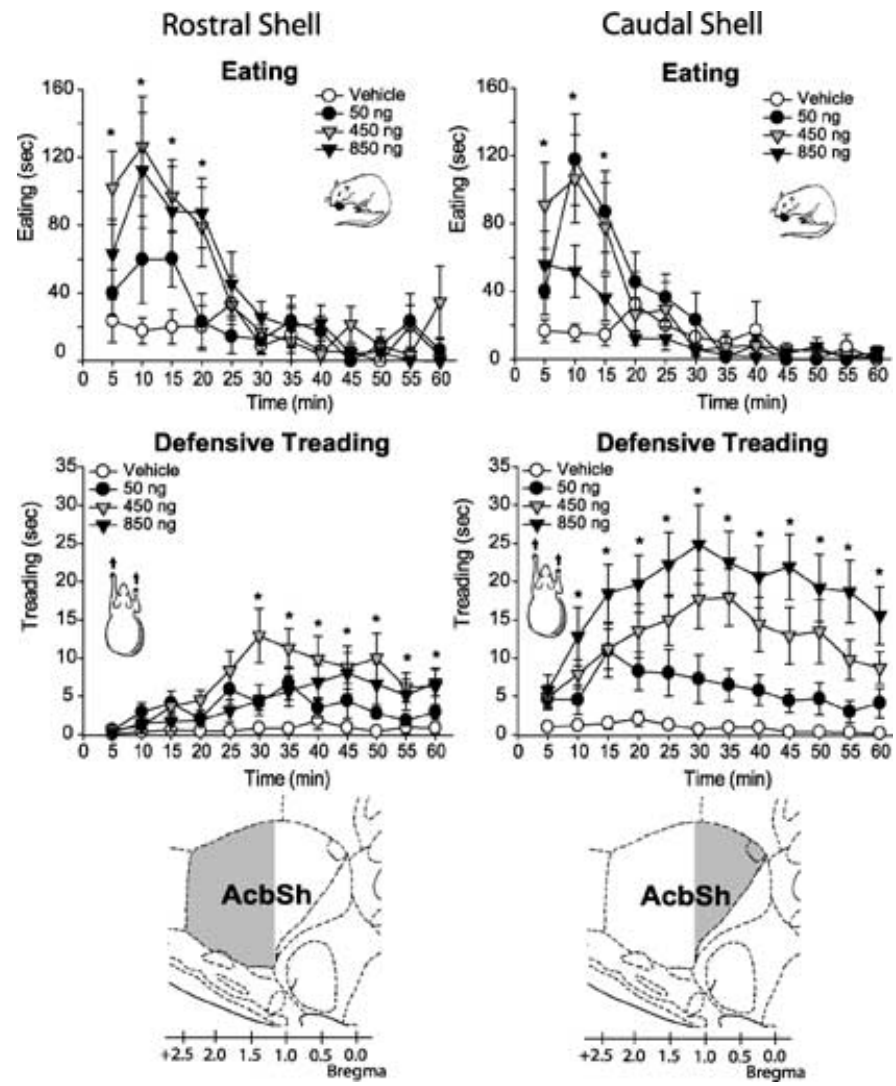

Fig. 5. Time course (successive 5-min bins over $1 \mathrm{~h}$ ) of eating and defensive treading behaviour elicited by DNQX microinjection into accumbens shell. Eating behaviour (top) was enhanced immediately after DNQX microinjection and typically lasted only 15-20 min. Conversely, defensive treading (bottom) was elicited later in the session (after $10 \mathrm{~min}$ in caudal shell and $30 \mathrm{~min}$ in rostral shell) and continued for extensive time periods, at least until the end of the 60 -min session. ${ }^{*} P<0.05$ vs. vehicle.

$\left(F_{1,106}=8.64, P<0.04\right)$ (Fig. 6). Caudal shell doses of 450 and $850 \mathrm{ng}$ both increased combined defensive bites, distress vocalizations and escape dashes $(P<0.01$ each), whereas only the highest dose, $850 \mathrm{ng}$, increased them at rostral sites $(P<0.05)$. This pattern of more enhanced fearfulness after caudal shell DNQX compared to rostral DNQX was confirmed by incidence analysis of the percentage of rats which emitted each defensive reaction $\left(\chi^{2}, P<0.03\right)$. For example, caudal $850 \mathrm{ng}$ DNQX caused $93 \%$ of rats to display at least one of these fearful behaviours compared to only $50 \%$ of rats which received the same dose at rostral sites $(P<0.05)$. Even more striking, rostral animals only displayed at most a single distress vocalization or a single escape dash, and never emitted a defensive bite, whereas $\approx 40 \%$ of rats with caudal shell sites exhibited a double or triple combination of bites, escape dashes and distress vocalizations mixed together (and $22 \%$ tried to bite the experimenter; Fig. 6).

\section{Experiment 2: place conditioning}

DNQX microinjections in shell established a rostrocaudal gradient of negative conditioned place avoidance (two-way ANOVA for dose $F_{1,47}=75.69 ; P<0.001$; Figs 7 and 8 ). This univalent avoidance gradient was reflected in stronger conditioned place avoidance after caudal shell DNQX pairings than after rostral shell pairing (rostral, $25 \%$ mean avoidance; caudal, $55 \%$ mean avoidance; $F_{1,47}=13.79$, $P<0.001$; Fig. 8). For caudal shell, $83 \%$ of sites caused strong avoidance $(>25 \%$ avoidance) and no caudal site failed to cause at 

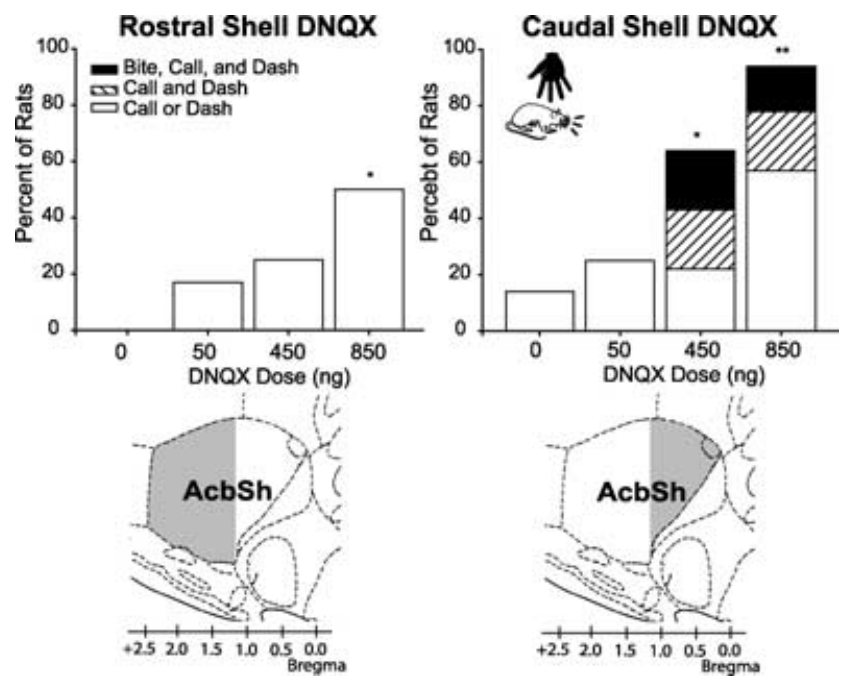

FIG. 6. Defensive bites, vocalizations and escape dashes, displayed at the end of the test session when the rat was picked up by an experimenter, elicited by DNQX microinjections into accumbens shell (plotted as percentage of animals displaying each type of fear behaviour). Caudal shell DNQX injections often caused triple combinations of defensive bites, vocalizations and escape dashes, and were the only sites to reliably increase bite attempts directed at the experimenter. Rostral sites only caused single vocalizations or escapes. ${ }^{*} P<0.05,{ }^{* *} P<0.001$ vs. vehicle.
DNQX Place Avoidance

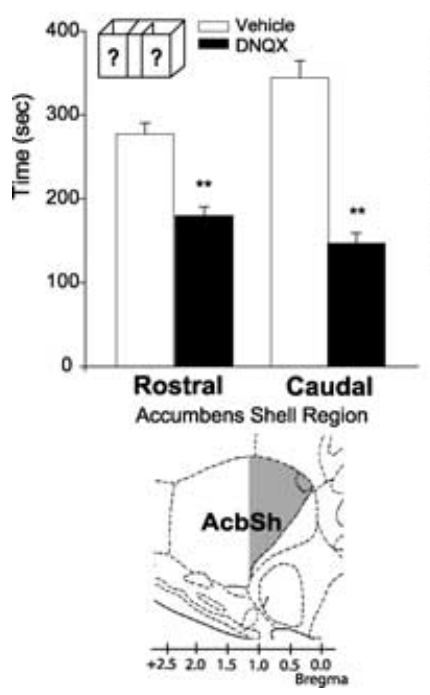
Place Avoidance

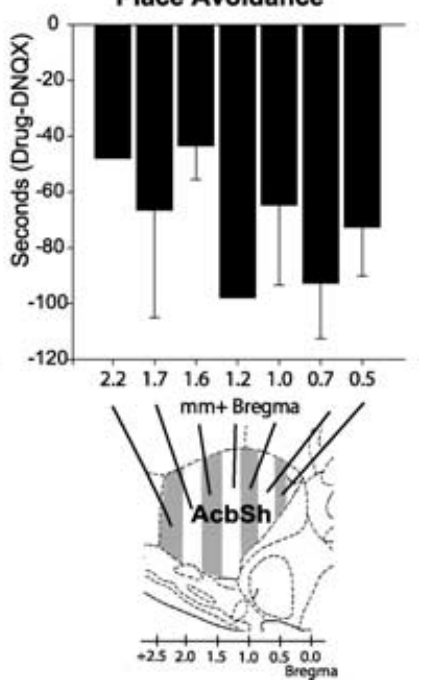

Anatomical Breakdown of DNQX

FIG. 7. Place conditioning produced by DNQX microinjection into accumbens medial shell sites. (Left) DNQX produced only conditioned place avoidance from both rostral and caudal shell. (Right) Anatomical breakdown of DNQXelicited place avoidance revealed a weak-to-strong rostrocaudal gradient in the magnitude of avoidance conditioning. ${ }^{*} P<0.05 ;{ }^{* *} P<0.001$ vs. vehicle.

least $10 \%$ avoidance. For rostral shell, only $31 \%$ of sites met the criteria for strong avoidance and nearly a quarter of rostral sites caused no detectable avoidance at all (Fig. 8). However, significant place avoidances overall were established by DNQX at both accumbens shell sites compared to vehicle pairings (caudal sites $F_{1,23}=69.61$, $P<0.001$; rostral sites $\left.F_{1,23}=31.89, P<0.001\right)$.

Several rats whose microinjection sites fell bilaterally outside accumbens shell in accumbens core, ventral pallidum or septum displayed no detectable conditioned place preference or avoidance

\section{Place Conditioning}
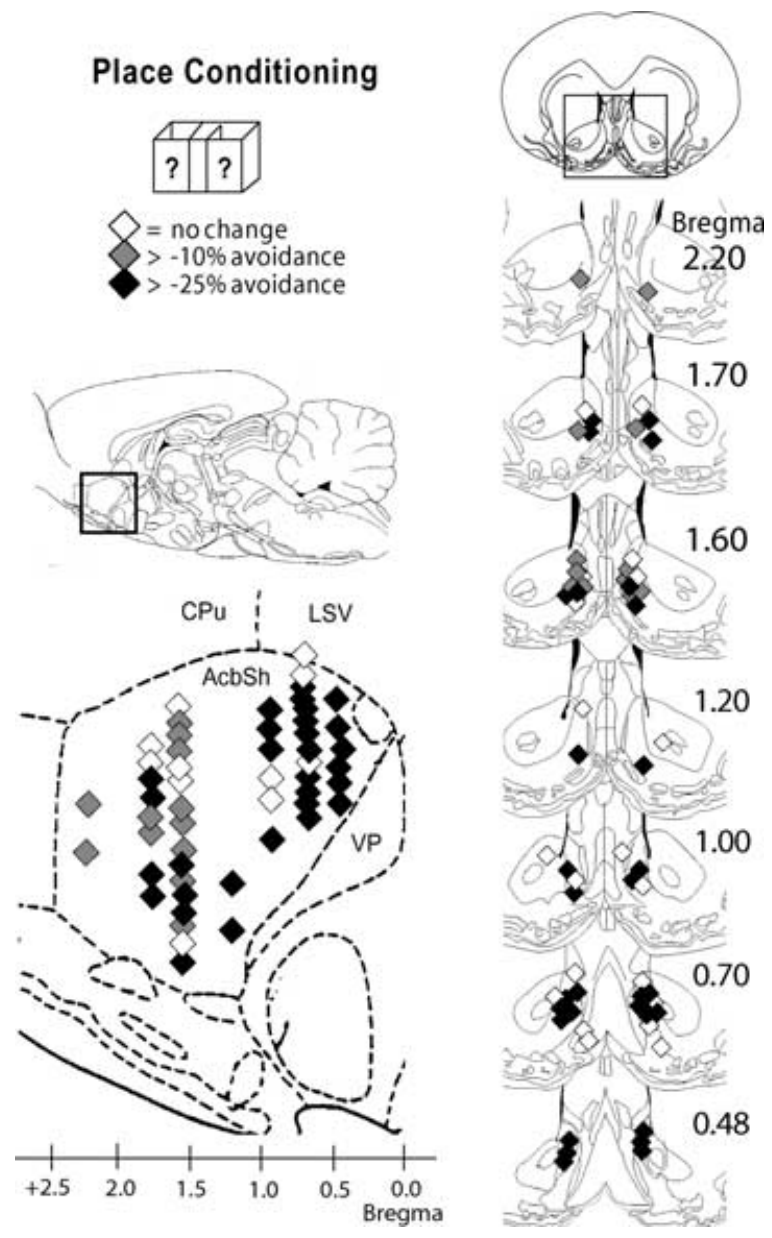

FIG. 8. Saggital and coronal functional maps of DNQX-elicited conditioned place avoidance from accumbens medial shell. DNQX produced conditioned place avoidance along a weak-to-strong rostrocaudal gradient. Microinjection sites which elicited strong place avoidance are concentrated in caudal shell regions.

after DNQX pairings (Fig. 8). These negative sites agree with results from experiment 1 , and overall negative sites for feeding, treading, biting and place conditioning were found just dorsal to the shell in the vertical band $(n=6)$ and in the septum $(n=3)$ and ventral pallidum $(n=2)$.

\section{Discussion}

Blockade of AMPA/kainate glutamate receptors in the medial shell of nucleus accumbens caused appetitive eating behaviour, defensive treading behaviour, defensive bites and distress calls, all along rostrocaudal gradients of positive-to-negative motivational valence. DNQX microinjections in rostral shell (rostral to $1.1 \mathrm{~mm}$ anterior to bregma) most effectively increased food intake, as earlier reported by Kelley and colleagues (Maldonado-Irizarry et al., 1995; Kelley \& Swanson, 1997; Stratford et al., 1998). Conversely, DNQX microinjections in caudal shell (caudal to $1.1 \mathrm{~mm}$ anterior to bregma) most effectively elicited defensive treading behaviour during the same test, and caused fearful bites and distress calls to be elicited at the end of the test session when the rat was touched by the experimenter. These results support the hypothesis that glutamate signals to rostral vs. caudal microcircuits in medial shell may differentially carry appetitive vs. aversive channels of motivational information. 
AMPA/kainate receptors in the medial shell appear most crucial for generating a glutamatergic positive-to-negative rostrocaudal gradient in motivation. DNQX microinjection into medial shell produced feeding at rostral sites and defensive behaviour at caudal sites as described above. However, NMDA receptor blockade by MK-801 at similar shell sites only suppressed food intake and elicited mild defensive treading at all sites, with no hint of rostrocaudal gradient. In the accumbens core a reverse rostrocaudal gradient, if anything, characterized defensive treading after AMPA/kainate blockade. In the core, only weak treading occurred and only after rostral DNQX. Similarly, eating behaviour was elicited by DNQX in the core only sporadically, only slightly, and without rostrocaudal gradient. Thus we conclude that glutamate blockade produces rostrocaudal gradients of appetitive-aversive motivation in accumbens shell but not in accumbens core, and within the shell by blockade of AMPA/kainate receptors but not NMDA receptors.

\section{Glutamate receptor subtype differences}

Why does AMPA/kainate blockade but not NMDA blockade in shell produce rostrocaudal gradients of positive-negative motivational valence? One possibility is that behavioural fear and feeding differences between AMPA/kainate and NMDA antagonists may be due to the different anatomical distributions of these receptor subtypes on presynaptic or postsynaptic elements of accumbens neurons. Glutamate AMPA receptors in accumbens are located mainly on postsynaptic dendrites of medium spiny GABAergic neurons, whereas kainate and NMDA receptors have a relatively higher proportion located on presynaptic axon terminals from hippocampus and cortex, in addition to postsynaptic sites (Tarazi et al., 1998a, b). In addition, it has been reported that DNQX and other AMPA antagonists suppress stimulation-induced excitatory postsynaptic potentials in accumbens more effectively than do NMDA antagonists (Pennartz et al., 1990, 1991; Hu \& White, 1996). Thus, DNQX microinjections which block postsynaptic AMPA receptors may have more effectively hyperpolarized local accumbens microcircuits by blocking excitatory inputs (Uchimura et al., 1989; Pennartz et al., 1990, 1991; Hu \& White, 1996; Crowder \& Weiner, 2002). The suggestion that postsynaptic hyperpolarization of local microcircuits in accumbens shell may be key to inducing rostrocaudal gradients of motivated feeding vs. fearful behaviours would be consistent with our previous demonstrations that GABA $_{\mathrm{A}}$ agonist microinjections cause similar gradients of positive-tonegative motivational valence.

Another possible explanation for rostrocaudal gradients of bivalent motivation after blockade of AMPA/kainate receptors, but not NMDA receptors, is the different molecular organization and intracellular effects of these receptor subtypes. AMPA, kainate and NMDA receptors are composed of different molecular subunits, and there is some evidence that subunit composition can influence receptor function (Malinow \& Malenka, 2002; Mead \& Stephens, 2003). Finally, there is a possibility that dopamine, which itself modulates appetitive and defensive behaviour (Salamone, 1994; Berridge \& Robinson, 1998; Horvitz, 2000; Koob \& Le Moal, 2001; Salamone \& Correa, 2002), may also modulate glutamate-related rostrocaudal gradients of motivational valence, and may interact specifically with receptor subtypes (Hotsenpiller et al., 2001; Chao et al., 2002; Park et al., 2002; Ikeda et al., 2003). Glutamate antagonists in accumbens not only increase food intake as shown here but also potently increase local dopamine levels during feeding behaviour (Taber \& Fibiger, 1997). Complex and reciprocal dopamine-glutamate interactions have been shown to modulate many types of motivational processes (Smith-Roe \& Kelley, 2000; Vanderschuren \& Kalivas, 2000; Cornish \& Kalivas, 2001; Pulvirenti \& Diana, 2001; Kiyatkin, 2002), and deserve further investigation regarding rostrocaudal gradients of fear and feeding behaviours.

\section{Accumbens core-shell differences}

Only the shell of nucleus accumbens generated positive-to-negative rostrocaudal gradients of motivated behaviour after DNQX microinjections. The same microinjections in accumbens core caused only weak and sporadic behavioural effects (with a very slight rostral core advantage for both valences of feeding and fear, if any gradient at all). A unique role for accumbens shell in generating feeding and fear gradients is consistent with both behavioural work and neuroanatomical connections which suggest the shell may be more involved than the core in mediating motivational and emotional processes (Heimer et al., 1991; Zahm \& Brog, 1992; Zahm \& Heimer, 1993; Heimer et al., 1997; Everitt et al., 1999; Kelley, 1999; Cardinal et al., 2002).

Perhaps the most important issue here is how local ensembles within the shell generate rostrocaudal gradients of positive-negative motivation. Why do rostral shell microinjections of DNQX or muscimol produce positive appetitive behaviours whereas caudal microinjections produce negative fearful behaviours? We can only note that the rostral shell differs from the caudal shell in both anatomical connections (Phillipson \& Griffiths, 1985; Wright et al., 1996; Gorelova \& Yang, 1997; Totterdell \& Meredith, 1997; Mulder et al., 1998; Groenewegen et al., 1999; Ding et al., 2001; French \& Totterdell, 2002) and neurochemical composition (Zaborszky et al., 1985; Bardo \& Hammer, 1991; Tribollet et al., 1992; Voorn \& Docter, 1992; Berridge et al., 1997; Delfs et al., 1998). It is not yet clear how neurobiological differences between rostral and caudal shell relate to its generation of rostrocaudal gradients of bivalent motivation. However, the various differences between rostral and caudal shell suggest that microcircuits in those regions may be differently embedded in larger mesocorticolimbic circuits involving ventral pallidum, cortex and other structures that mediate motivational and cognitive processing (Sarter \& Bruno, 1997; Swanson, 2000; Turchi \& Sarter, 2001; Neigh-McCandless et al., 2002). Our results also suggest that there may be segregated channels of motivational valence signals within such larger brain circuits.

\section{Comparison of glutamatergic and GABAergic gradients}

The shell glutamate (DNQX) gradients described here are quite similar to the GABAergic rostrocaudal positive-to-negative gradients for eliciting feeding and fear behaviour we previously reported (Reynolds $\&$ Berridge, 2001, 2002). However, there are a few differences. For example, $>40 \%$ of DNQX microinjections in medial shell elicited both feeding and fear behaviours in the same rat. In our earlier GABAergic studies $<10 \%$ of muscimol microinjections elicited such ambivalent fear or feeding behaviours. Also, GABAergic microinjections produce a bivalent rostrocaudal gradient of conditioned place preference or avoidance which mirrors their feeding or fear gradient of elicited behaviour. By contrast, glutamatergic blockade here produced a univalent gradient of conditioned place avoidance which increased monotonically at caudal shell sites.

Several explanations might account for the greater ability of DNQX glutamatergic blockade to simultaneously elicit both appetitive and defensive behaviours, whereas GABA tended more to elicit only one motivational valence or the other. First, in the present study, DNQX was dissolved in a DMSO-saline vehicle which is more lipophilic than the saline used as vehicle for muscimol, and hence DNQX may have diffused to a larger extent. However, diffusion could not have been very great, because DNQX in the vertical limb of the diagonal band, septum or ventral pallidum adjacent to the shell did not produce either appetitive eating or defensive treading behaviour. 
Alternatively, the glutamate-GABA difference might be explained if accumbens neurons are more potently hyperpolarized by muscimol activation of $\mathrm{GABA}_{\mathrm{A}}$ receptors on somata and proximal dendrites (Sun \& Cassell, 1993; Johnson et al., 1994a) than by blockade of glutamate AMPA/kainate receptors on distal dendritic spines (Meredith \& Wouterlood, 1990; Meredith et al., 1990; Sesack \& Pickel, 1992; Johnson et al., 1994b). Stronger hyperpolarization of shell neuronal ensembles might conceivably produce sharper motivational valence gradients. If so, it indicates that a single microcircuit might be capable of producing more than one motivational valence, depending on its intensity of hyperpolarization (or duration or constancy of hyperpolarization). The hypothesis that a shell microcircuit may have multiple modes of function is also compatible with many reports that opioid and dopamine agents in accumbens shell have primarily positive motivational effects on behaviour even at caudal shell sites (Bakshi \& Kelley, 1993; Peciña \& Berridge, 2000; Wyvell \& Berridge, 2000; Zhang \& Kelley, 2000). Opioid and dopamine agents would be expected to have complex mixed hyperpolarization and depolarization effects rather than pure hyperpolarization of local microcircuits (Jiang \& North, 1992; O’Donnell \& Grace, 1995; Hu \& White, 1997; Nicola \& Malenka, 1997; O’Donnell, 1999).

The hypothesis that glutamate blockade often produces mixed fear and feeding motivational effects might also help explain why DNQX produces conditioned avoidance even at the most rostral 'eating sites' (in addition to causing doubled intensity of conditioned place avoidance at more caudal 'fear sites'). It has been suggested that mesolimbic systems, including dopamine projections to accumbens spiny neurons, mediate positive incentive salience but, under some conditions, mediate instead an ambivalent or even negatively valenced fearful salience (Robinson \& Berridge, 1993; Berridge \& Robinson, 1998; Gray et al., 1999; Berridge, 2001; Kapur, 2003). If DNQX in rostral shell causes bivalent or ambiguous motivational salience to be assigned to neural representations of external stimuli, partly weighted by rostrocaudal placement, then the motivational valence of a particular stimulus might also partly depend on intrinsic stimulus features and on past experience, as well as on the DNQX microinjection.

For example, food sight and odour may be most likely to be attributed specifically with positive incentive salience after rostral or middle shell hyperpolarization, because chow pellets are familiar incentive objects which have often had positive hedonic impact in the past. Even if rostral shell DNQX does not elicit all the features of hunger, as seems true for rostral shell GABA (Maldonado-Irizarry et al., 1995; Kelley \& Swanson, 1997; Stratford \& Kelley, 1997; Reynolds \& Berridge, 2002), shell activation of positive or mixed motivational salience attributed to perceived food could cause eating behaviour. However, a novel place context (such as a place-conditioning apparatus) lacks the positive bias of food stimuli, and may even have slight negative bias for a neophobic rat. Modulation of behavioural fear-feeding valence by stimulus type would occur even more for glutamate blockade than for GABA microinjection, if DNQX elicits motivational salience which is more mixed in positive-negative valence. Thus a novel place may be more likely to be interpreted fearfully when attributed with the same mixture of motivational salience, producing conditioned place avoidance. Such flexibility in accumbens shell ensembles may hold adaptive value by allowing factors such as environment or past experience to influence motivated behaviour.

\section{Clinical implications}

Drugs of abuse such as phencyclidine and other glutamate antagonists can cause paranoid psychotic symptoms in human drug users which, it has been suggested, mimic schizophrenia better than either ampheta- mine or LSD (Cohen et al., 1966; Javitt \& Zukin, 1991; Jentsch \& Roth, 1999; Sawa \& Snyder, 2002). Phencyclidine is an NMDA antagonist, but repeated administration also suppresses accumbens AMPA receptor binding (Ellison et al., 1999). Repeated use of some nonglutamatergic drugs that also cause paranoid psychotic symptoms, such as cocaine (Bartlett et al., 1997), similarly suppresses the ratio of AMPA : NMDA receptor-mediated postsynaptic currents in accumbens shell and amplifies dopamine-induced inhibition of AMPA-mediated synaptic responses (Thomas et al., 2001; Beurrier \& Malenka, 2002).

It has been suggested that human schizophrenia involves reduced glutamatergic input to the ventral striatum (Bachus \& Kleinman, 1996; Csernansky \& Bardgett, 1998). Decreased levels of accumbens glutamate uptake sites and of AMPA, but not NMDA, receptor binding have been reported in schizophrenics (Aparicio-Legarza et al., 1997; Noga \& Wang, 2002). As an explanatory hypothesis for the positive motivational symptoms of schizophrenia, Kapur recently suggested that elevated mesocorticolimbic function causes excessive incentive salience to be attributed to otherwise innocuous stimuli and events, so that those stimuli or events become perceived as excessively meaningful by psychotic individuals (Kapur, 2003). While acknowledging the gap between human psychopathology and animal affective neuroscience studies, our results support the idea that mesocorticolimbic dysfunction can cause abnormal motivational salience to be assigned to stimuli, resulting in excessive fascination or fear. Though purely speculative, extrapolation from our results suggests that caudal shell hyperpolarization might produce fearful psychosis symptoms in humans, whereas broader hyperpolarization of both rostral and caudal shell might produce symptoms involving both paranoia and excessive positive incentive motivation too. Aversive and defensive aspects of paranoid psychoses seem especially consistent with the possibility of suppressed AMPA signals in human caudal accumbens shell, which might cause excessive negative motivational salience in schizophrenia (Kapur, 2003).

\section{Conclusions}

These results support suggestions that multiple functional ensembles exist in the nucleus accumbens, modulated by differential glutamate neurotransmission (O'Donnell et al., 1999). When hyperpolarized by blockade of excitatory AMPA/kainate signals, rostral and caudal shell microcircuits generate motivated behaviour of opposite motivational valence. Such bivalent gradients indicate that glutamatergic mesocorticolimbic circuits may map appetitive and aversive channels of information via segregated rostrocaudal microcircuits in the medial shell.

\section{Acknowledgements}

This research was supported by grants from NSF (IBN 0091661) and NIH (MH 63649) to K.C.B. and an NIH predoctoral fellowship (DA14679) to S.M.R.

\section{Abbreviations}

DNQX, 6,7-dinitroquinoxaline-2,3(1H,4H)-dione; MK-801, dizocilpine.

\section{References}

Aparicio-Legarza, M.I., Cutts, A.J., Davis, B. \& Reynolds, G.P. (1997) Deficits of $\left[{ }^{3} \mathrm{H}\right] \mathrm{D}$-aspartate binding to glutamate uptake sites in striatal and accumbens tissue in patients with schizophrenia. Neurosci. Lett., 232, 13-16.

Bachus, S.E. \& Kleinman, J.E. (1996) The neuropathology of schizophrenia. J. Clin. Psychiatry, 57, 72-83.

Bakshi, V.P. \& Kelley, A.E. (1993) Feeding induced by opioid stimulation of the ventral striatum - role of opiate receptor subtypes. J. Pharmacol. Exp. Ther, 265, $1253-1260$. 
Bardo, M.T. \& Hammer, R.P., Jr (1991) Autoradiographic localization of dopamine D1 and D2 receptors in rat nucleus accumbens: resistance to differential rearing conditions. Neuroscience, 45, 281-290.

Bartlett, E., Hallin, A., Chapman, B. \& Angrist, B. (1997) Selective sensitization to the psychosis-inducing effects of cocaine: a possible marker for addiction relapse vulnerability? Neuropsychopharmacology, 16, 77-82.

Basso, A.M. \& Kelley, A.E. (1999) Feeding induced by GABA (A) receptor stimulation within the nucleus accumbens shell: regional mapping and characterization of macronutrient and taste preference. Behav. Neurosci., 113, 324-336.

Beckstead, R.M. (1979) An autoradiographic examination of corticocortical and subcortical projections of the mediodorsal-projection (prefrontal) cortex in the rat. J. Comp. Neurol., 184, 43-62.

Berridge, K.C. (2001) Reward learning: Reinforcement, incentives, and expectations. In Medin, D.L. (ed.), The Psychology of Learning and Motivation. Academic Press, NY, pp. 223-278.

Berridge, C.W., Mitton, E., Clark, W. \& Roth, R.H. (1999) Engagement in a non-escape (displacement) behavior elicits a selective and lateralized suppression of frontal cortical dopaminergic utilization in stress. Synapse, 32, 187-197.

Berridge, K.C. \& Robinson, T.E. (1998) What is the role of dopamine in reward: hedonic impact, reward learning, or incentive salience? Brain Res. Rev., 28 309-369.

Berridge, C.W., Stratford, T.L., Foote, S.L. \& Kelley, A.E. (1997) Distribution of dopamine beta-hydroxylase-like immunoreactive fibers within the shell subregion of the nucleus accumbens. Synapse, 27, 230-241.

Beurrier, C. \& Malenka, R.C. (2002) Enhanced inhibition of synaptic transmission by dopamine in the nucleus accumbens during behavioral sensitization to cocaine. J. Neurosci., 22, 5817-5822.

Blackburn, J.R., Pfaus, J.G. \& Phillips, A.G. (1992) Dopamine functions in appetitive and defensive behaviours. Prog. Neurobiol., 39, 247-279.

Cardinal, R.N., Parkinson, J.A., Hall, J. \& Everitt, B.J. (2002) Emotion and motivation: the role of the amygdala, ventral striatum, and prefrontal cortex. Neurosci. Biobehav. Rev., 26, 321-352.

Chao, S.Z., Ariano, M.A., Peterson, D.A. \& Wolf, M.E. (2002) D1 dopamine receptor stimulation increases GluR1 surface expression in nucleus accumbens neurons. J. Neurochem., 83, 704-712.

Christie, M.J., Summers, R.J., Stephenson, J.A., Cook, C.J. \& Beart, P.M. (1987) Excitatory amino acid projections to the nucleus accumbens septi in the rat: a retrograde transport study utilizing $\mathrm{D}\left[{ }^{3} \mathrm{H}\right]$ aspartate and $\left[{ }^{3} \mathrm{H}\right] \mathrm{GABA}$. Neuroscience, 22, 425-439.

Churchill, L. \& Kalivas, P.W. (1994) A topographically organized gammaaminobutyric acid projection from the ventral pallidum to the nucleus accumbens in the rat. J. Comp. Neurol., 345, 579-595.

Cohen, B.D., Rosenbaum, G., Luby, E.D. \& Gottlieb, J.S. (1966) Comparison of phencyclidine hydrochloride (Sernyl) with other drugs. Arch. Gen. Psychiatry, 6, 395-401.

Cornish, J.L. \& Kalivas, P.W. (2001) Cocaine sensitization and craving: differing roles for dopamine and glutamate in the nucleus accumbens. J. Addict. Dis., 20, 43-54.

Crowder, T.L. \& Weiner, J.L. (2002) Functional characterization of kainate receptors in the rat nucleus accumbens core region. J. Neurophysiol., 88 41- 48 .

Csernansky, J.G. \& Bardgett, M.E. (1998) Limbic-cortical neuronal damage and the pathophysiology of schizophrenia. Schizophr. Bull., 24, 231-248.

Delfs, J.M., Zhu, Y., Druhan, J.P. \& Aston-Jones, G.S. (1998) Origin of noradrenergic afferents to the shell subregion of the nucleus accumbens: anterograde and retrograde tract-tracing studies in the rat. Brain Res., 806, $127-140$

Ding, D.C., Gabbott, P.L. \& Totterdell, S. (2001) Differences in the laminar origin of projections from the medial prefrontal cortex to the nucleus accumbens shell and core regions in the rat. Brain Res., 917, 81-89.

Ellison, G., Keys, A. \& Noguchi, K. (1999) Long-term changes in brain following continuous phencyclidine administration: an autoradiographic study using flunitrazepam, ketanserin, mazindol, quinuclidinyl benzilate, piperidyl-3,4-3H (N)-TCP, and AMPA receptor ligands. Pharmacol. Toxicol., 84, 9-17.

Everitt, B.J., Dickinson, A. \& Robbins, T.W. (2001) The neuropsychological basis of addictive behaviour. Brain Res. Rev., 36, 129-138.

Everitt, B.J., Parkinson, J.A., Olmstead, M.C., Arroyo, M., Robledo, P. \& Robbins, T.W. (1999) Associative processes in addiction and reward. The role of amygdala-ventral striatal subsystems. Ann. NY Acad. Sci., 877, 412-438.

French, S.J. \& Totterdell, S. (2002) Hippocampal and prefrontal cortical inputs monosynaptically converge with individual projection neurons of the nucleus accumbens. J. Comp. Neurol., 446, 151-165.
Fuller, T.A., Russchen, F.T. \& Price, J.L. (1987) Sources of presumptive glutamergic/aspartergic afferents to the rat ventral striatopallidal region. J. Comp. Neurol., 258, 317-338.

Gorelova, N. \& Yang, C.R. (1997) The course of neural projection from the prefrontal cortex to the nucleus accumbens in the rat. Neuroscience, 76, 689-706.

Gracy, K.N., Svingos, A.L. \& Pickel, V.M. (1997) Dual ultrastructural localization of mu-opioid receptors and NMDA-type glutamate receptors in the shell of the rat nucleus accumbens. J. Neurosci., 17, 4839-4848.

Gray, J.A., Kumari, V., Lawrence, N. \& Young, A.M.J. (1999) Functions of the dopaminergic innervation of the nucleus accumbens. Psychobiology, 27, $225-235$.

Groenewegen, H.J., Mulder, A.B., Beijer, A.V., Wright, C.I., Lopes da Silva, F.H. \& Pennartz, C.M. (1999) Hippocampal and amygdaloid interactions in the nucleus accumbens. Psychobiology, 27, 149-164.

Heimer, L., Alheid, G.F., de Olmos, J.S., Groenewegen, H.J., Haber, S.N., Harlan, R.E. \& Zahm, D.S. (1997) The accumbens: beyond the core-shell dichotomy. J. Neuropsychiatry Clin. Neurosci., 9, 354-381.

Heimer, L., Zahm, D.S., Churchill, L., Kalivas, P.W. \& Wohltmann, C. (1991) Specificity in the projection patterns of accumbal core and shell in the rat. Neuroscience, 41, 89-125.

Horvitz, J.C. (2000) Mesolimbocortical and nigrostriatal dopamine responses to salient non-reward events. Neuroscience, 96, 651-656.

Hotsenpiller, G., Giorgetti, M. \& Wolf, M.E. (2001) Alterations in behaviour and glutamate transmission following presentation of stimuli previously associated with cocaine exposure. Eur. J. Neurosci., 14, 1843-1855.

Hu, X.T. \& White, F.J. (1996) Glutamate receptor regulation of rat nucleus accumbens neurons in vivo. Synapse, 23, 208-218.

Hu, X.T. \& White, F.J. (1997) Dopamine enhances glutamate-induced excitation of rat striatal neurons by cooperative activation of D1 and D2 class receptors. Neurosci. Lett., 224, 61-65.

Ikeda, H., Akiyama, G., Fujii, Y., Minowa, R., Koshikawa, N. \& Cools, A.R. (2003) Role of AMPA and NMDA receptors in the nucleus accumbens shell in turning behaviour of rats: interaction with dopamine receptors. Neuropharmacology, 44, 81-87.

Javitt, D.C. \& Zukin, S.R. (1991) Recent advances in the phencyclidine model of schizophrenia. Am. J. Psychiatry, 148, 1301-1308.

Jentsch, J.D. \& Roth, R.H. (1999) The neuropsychopharmacology of phencyclidine: from NMDA receptor hypofunction to the dopamine hypothesis of schizophrenia. Neuropsychopharmacology, 20, 201-225.

Jiang, Z.G. \& North, R.A. (1992) Pre- and postsynaptic inhibition by opioids in rat striatum. J. Neurosci., 12, 356-361.

Johnson, L.R., Aylward, R.L. \& Totterdell, S. (1994a) Convergence of limbic afferents and the mesolimbic dopamine system in the nucleus accumbens: Anatomical studies in the rat. In Haslam, C., Ewing, J., Farnbach, R., Johns, U. \& Weekes, B. (eds), Cognitive Functions in Health, Disease and Disorder. Australian Academic Press, Brisbane, pp. 137-144.

Johnson, L.R., Aylward, R.L. \& Totterdell, S. (1994b) Synaptic organization of the amygdalar input to the nucleus accumbens in the rat. In Percheron, G., McKenzie, J.S. \& Feger, J.S. (eds), Basal Ganglia IV. Plenum, New York.

Kapur, S. (2003) Psychosis as state of aberrant salience: a framework linking biology, phenomenology, and pharmacology in schizophrenia. Am. J. Psychiatry, 160, 13-23.

Kawaguchi, Y., Wilson, C.J., Augood, S.J. \& Emson, P.C. (1995) Striatal interneurones: chemical, physiological and morphological characterization. Trends Neurosci., 18, 527-535.

Kelley, A.E. (1999) Neural integrative activities of nucleus accumbens subregions in relation to learning and motivation. Psychobiology, 27, 198-213.

Kelley, A.E. \& Swanson, C.J. (1997) Feeding induced by blockade of AMPA and kainate receptors within the ventral striatum: a microinfusion mapping study. Behav. Brain Res., 89, 107-113.

Kiyatkin, E.A. (2002) Dopamine in the nucleus accumbens: cellular actions, drug- and behavior-associated fluctuations, and a possible role in an organism's adaptive activity. Behav. Brain Res., 137, 27-46.

Koob, G.F. (1999) The role of the striatopallidal and extended amygdala systems in drug addiction. Ann. NY Acad. Sci., 877, 445-460.

Koob, G.F. \& Le Moal, M. (2001) Drug addiction, dysregulation of reward, and allostasis. Neuropsychopharmacology, 24, 97-129.

Londei, T., Valentini, A.M. \& Leone, V.G. (1998) Investigative burying by laboratory mice may involve non-functional, compulsive, behaviour. Behav. Brain Res., 94, 249-254.

Maldonado-Irizarry, C.S., Swanson, C.J. \& Kelley, A.E. (1995) Glutamate receptors in the nucleus accumbens shell control feeding behavior via the lateral hypothalamus. J. Neurosci., 15, 6779-6788. 
Malinow, R. \& Malenka, R.C. (2002) AMPA receptor trafficking and synaptic plasticity. Annu. Rev. Neurosci., 25, 103-126.

McBride, W.J., Murphy, J.M. \& Ikemoto, S. (1999) Localization of brain reinforcement mechanisms: intracranial self-administration and intracranial place-conditioning studies. Behav. Brain Res., 101, 129-152.

McDonald, A.J. (1991) Organization of amygdaloid projections to the prefrontal cortex and associated striatum in the rat. Neuroscience, 44, 1-14.

Mead, A.N. \& Stephens, D.N. (2003) Selective disruption of stimulus-reward learning in glutamate receptor gria1 knock-out mice. J. Neurosci., 23, 10411048.

Meredith, G.E. (1999) The synaptic framework for chemical signaling in nucleus accumbens. Ann. NY Acad. Sci., 877, 140-156.

Meredith, G.E., Pennartz, C.M. \& Groenewegen, H.J. (1993) The cellular framework for chemical signalling in the nucleus accumbens. Prog. Brain Res., 99, 3-24.

Meredith, G.E. \& Wouterlood, F.G. (1990) Hippocampal and midline thalamic fibers and terminals in relation to the choline acetyltransferase-immunoreactive neurons in nucleus accumbens of the rat: a light and electron microscopic study. J. Comp. Neurol., 296, 204-221.

Meredith, G.E., Wouterlood, F.G. \& Pattiselanno, A. (1990) Hippocampal fibers make synaptic contacts with glutamate decarboxylase-immunoreactive neurons in the rat nucleus accumbens. Brain Res., 513, 329-334.

Mulder, A.B., Hodenpijl, M.G. \& Lopes da Silva, F.H. (1998) Electrophysiology of the hippocampal and amygdaloid projections to the nucleus accumbens of the rat: convergence, segregation, and interaction of inputs. J. Neurosci., 18, 5095-5102.

Neigh-McCandless, G., Kravitz, B.A., Sarter, M. \& Bruno, J.P. (2002) Stimulation of cortical acetylcholine release following blockade of ionotropic glutamate receptors in nucleus accumbens. Eur. J. Neurosci., 16, 1259-1266.

Nicola, S.M. \& Malenka, R.C. (1997) Dopamine depresses excitatory and inhibitory synaptic transmission by distinct mechanisms in the nucleus accumbens. J. Neurosci., 17, 5697-5710.

Noga, J.T. \& Wang, H. (2002) Further postmortem autoradiographic studies of AMPA receptor binding in schizophrenia. Synapse, 45, 250-258.

O'Donnell, P. (1999) Ensemble coding in the nucleus accumbens. Psychobiology, 27, 187-197.

O'Donnell, P. \& Grace, A.A. (1993) Physiological and morphological properties of accumbens core and shell neurons recorded in vitro. Synapse, 13, $135-160$.

O’Donnell, P. \& Grace, A.A. (1995) Synaptic interactions among excitatory afferents to nucleus accumbens neurons: hippocampal gating of prefrontal cortical input. J. Neurosci., 15, 3622-3639.

O’Donnell, P., Greene, J., Pabello, N., Lewis, B.L. \& Grace, A.A. (1999) Modulation of cell firing in the nucleus accumbens. Ann. NY Acad. Sci., 877, 157-175.

Owings, D.H. \& Coss, R.G. (1977) Snake mobbing by California ground squirrels - adaptive variation and ontogeny. Behaviour, 62, 50-69.

Owings, D.H. \& Morton, E.S. (1998) Animal Vocal Communication: a new approach. Cambridge University Press, Cambridge, New York.

Park, W.K., Bari, A.A., Jey, A.R., Anderson, S.M., Spealman, R.D., Rowlett, J.K. \& Pierce, R.C. (2002) Cocaine administered into the medial prefrontal cortex reinstates cocaine-seeking behavior by increasing AMPA receptormediated glutamate transmission in the nucleus accumbens. J. Neurosci., 22, 2916-2925.

Paxinos, P. \& Watson, C. (1997) The Rat Brain in Stereotaxic Coordinates, 3rd edn. Academic Press, Inc., London.

Peciña, S. \& Berridge, K.C. (2000) Opioid eating site in accumbens shell mediates food intake and hedonic 'liking': map based on microinjection Fos plumes. Brain Res., 863, 71-86.

Pennartz, C.M., Boeijinga, P.H., Kitai, S.T. \& Lopes da Silva, F.H. (1991) Contribution of NMDA receptors to postsynaptic potentials and paired-pulse facilitation in identified neurons of the rat nucleus accumbens in vitro. Exp. Brain Res., 86, 190-198.

Pennartz, C.M., Boeijinga, P.H. \& Lopes da Silva, F.H. (1990) Locally evoked potentials in slices of the rat nucleus accumbens: NMDA and non-NMDA receptor mediated components and modulation by GABA. Brain Res., 529, $30-41$.

Pennartz, C.M., Groenewegen, H.J. \& Lopes da Silva, F.H. (1994) The nucleus accumbens as a complex of functionally distinct neuronal ensembles: an integration of behavioural, electrophysiological and anatomical data. Prog. Neurobiol., 42, 719-761.

Phillipson, O.T. \& Griffiths, A.C. (1985) The topographic order of inputs to nucleus accumbens in the rat. Neuroscience, 16, 275-296.

Pulvirenti, L. \& Diana, M. (2001) Drug dependence as a disorder of neural plasticity: focus on dopamine and glutamate. Rev. Neurosci., 12, 141-158.
Rada, P., Tucci, S., Murzi, E. \& Hernandez, L. (1997) Extracellular glutamate increases in the lateral hypothalamus and decreases in the nucleus accumbens during feeding. Brain Res., 768, 338-340.

Reynolds, S.M. \& Berridge, K.C. (2001) Fear and feeding in the nucleus accumbens shell: rostrocaudal segregation of GABA-elicited defensive behavior versus eating behavior. J. Neurosci., 21, 3261-3270.

Reynolds, S.M. \& Berridge, K.C. (2002) Positive and negative motivation in nucleus accumbens shell: Bivalent rostrocaudal gradients for GABA-elicited eating, taste 'liking'/'disliking' reactions, place preference/avoidance, and fear. J. Neurosci., 22, 7308-7320.

Robinson, T.E. \& Berridge, K.C. (1993) The neural basis of drug craving: an incentive-sensitization theory of addiction. Brain Res. Rev., 18, 247-291.

Salamone, J.D. (1994) The involvement of nucleus accumbens dopamine in appetitive and aversive motivation. Behav. Brain Res., 61, 117-133.

Salamone, J.D. \& Correa, M. (2002) Motivational views of reinforcement: implications for understanding the behavioral functions of nucleus accumbens dopamine. Behav. Brain Res., 137, 3-25.

Sarter, M. \& Bruno, J.P. (1997) Cognitive functions of cortical acetylcholine: toward a unifying hypothesis. Brain Res. Rev., 23, 28-46.

Saulskaya, N.B. \& Marsden, C.A. (1997) Glutamate levels in the nucleus accumbens in a conditioned emotional response. Neurosci. Behav. Physiol., 27, 548-551.

Saulskaya, N. \& Marsden, C.A. (1995) Extracellular glutamate in the nucleus accumbens during a conditioned emotional response in the rat. Brain Res., 698, $114-120$

Saulskaya, N.B. \& Mikhailova, M.O. (2002) Feeding-induced decrease in extracellular glutamate level in the rat nucleus accumbens: dependence on glutamate uptake. Neuroscience, 112, 791-801.

Sawa, A. \& Snyder, S.H. (2002) Schizophrenia: diverse approaches to a complex disease. Science, 296, 692-695.

Sesack, S.R., Deutch, A.Y., Roth, R.H. \& Bunney, B.S. (1989) Topographical organization of the efferent projections of the medial prefrontal cortex in the rat: an anterograde tract-tracing study with Phaseolus vulgaris leucoagglutinin. J. Comp. Neurol., 290, 213-242.

Sesack, S.R. \& Pickel, V.M. (1992) Prefrontal cortical efferents in the rat synapse on unlabeled neuronal targets of catecholamine terminals in the nucleus accumbens septi and on dopamine neurons in the ventral tegmental area. J. Comp. Neurol., 320, 145-160.

Smith-Roe, S.L. \& Kelley, A.E. (2000) Coincident activation of NMDA and dopamine D1 receptors within the nucleus accumbens core is required for appetitive instrumental learning. J. Neurosci., 20, 7737-7742.

Spyraki, C., Kazandjian, A. \& Varonos, D. (1985) Diazepam-induced place preference conditioning: appetitive and antiaversive properties. Psychopharmacology, 87, 225-232.

Stratford, T.R. \& Kelley, A.E. (1997) GABA in the nucleus accumbens shell participates in the central regulation of feeding behavior. J. Neurosci., 17, $4434-4440$.

Stratford, T.R., Swanson, C.J. \& Kelley, A. (1998) Specific changes in food intake elicited by blockade or activation of glutamate receptors in the nucleus accumbens shell. Behav. Brain Res., 93, 43-50.

Sun, N. \& Cassell, M.D. (1993) Intrinsic GABAergic neurons in the rat central extended amygdala. J. Comp. Neurol., 330, 381-404.

Swanson, L.W. (2000) Cerebral hemisphere regulation of motivated behavior (1). Brain Res., 886, 113-164.

Taber, M.T. \& Fibiger, H.C. (1997) Feeding-evoked dopamine release in the nucleus accumbens: regulation by glutamatergic mechanisms. Neuroscience, 76, $1105-1112$.

Tarazi, F.I., Campbell, A. \& Baldessarini, R.J. (1998a) Effects of hippocampal lesions on striatolimbic ionotropic glutamatergic receptors. Neurosci. Lett., 250, 13-16.

Tarazi, F.I., Campbell, A., Yeghiayan, S.K. \& Baldessarini, R.J. (1998b) Localization of ionotropic glutamate receptors in caudate-putamen and nucleus accumbens septi of rat brain: comparison of NMDA, AMPA, and kainate receptors. Synapse, 30, 227-235.

Thomas, M.J., Beurrier, C., Bonci, A. \& Malenka, R.C. (2001) Long-term depression in the nucleus accumbens: a neural correlate of behavioral sensitization to cocaine. Nature Neurosci., 4, 1217-1223.

Totterdell, S. \& Meredith, G.E. (1997) Topographical organization of projections from the entorhinal cortex to the striatum of the rat. Neuroscience, 78, 715-729.

Tribollet, E., Barberis, C., Dubois-Dauphin, M. \& Dreifuss, J.J. (1992) Localization and characterization of binding sites for vasopressin and oxytocin in the brain of the guinea pig. Brain Res., 589, 15-23.

Turchi, J. \& Sarter, M. (2001) Bidirectional modulation of basal forebrain Nmethyl-D-aspartate receptor function differentially affects visual attention but not visual discrimination performance. Neuroscience, 104, 407-417. 
Tzschentke, T.M. (1998) Measuring reward with the conditioned place preference paradigm: a comprehensive review of drug effects, recent progress and new issues. Prog. Neurobiol., 56, 613-672.

Uchimura, N., Higashi, H. \& Nishi, S. (1989) Membrane properties and synaptic responses of the guinea pig nucleus accumbens neurons in vitro. J. Neurophysiol., 61, 769-779.

Van Bockstaele, E.J. \& Pickel, V.M. (1995) GABA-containing neurons in the ventral tegmental area project to the nucleus accumbens in rat brain. Brain Res., 682, 215-221.

Vanderschuren, L.J. \& Kalivas, P.W. (2000) Alterations in dopaminergic and glutamatergic transmission in the induction and expression of behavioral sensitization: a critical review of preclinical studies. Psychopharmacology (Berl.), 151, 99-120.

Voorn, P. \& Docter, G.J. (1992) A rostrocaudal gradient in the synthesis of enkephalin in nucleus accumbens. Neuroreport, 3, 161-164.

Wilkie, D.M., MacLennan, A.J. \& Pinel, J.P. (1979) Rat defensive behavior: burying noxious food. J. Exp. Anal. Behav., 31, 299-306.

Wise, R.A. (1998) Drug-activation of brain reward pathways. Drug Alcoh. Depend., 51, 13-22.
Wright, C.I., Beijer, A.V. \& Groenewegen, H.J. (1996) Basal amygdaloid complex afferents to the rat nucleus accumbens are compartmentally organized. J. Neurosci., 16, 1877-1893.

Wyvell, C.L. \& Berridge, K.C. (2000) Intra-accumbens amphetamine increases the conditioned incentive salience of sucrose reward: enhancement of reward 'wanting' without enhanced 'liking' or response reinforcement. J. Neurosci., 20, 8122-8130.

Zaborszky, L., Alheid, G.F., Beinfeld, M.C., Eiden, L.E., Heimer, L. \& Palkovits, M. (1985) Cholecystokinin innervation of the ventral striatum: a morphological and radioimmunological study. Neuroscience, 14, 427-453.

Zahm, D.S. \& Brog, J.S. (1992) On the significance of subterritories in the 'accumbens' part of the rat ventral striatum. Neuroscience, 50, 751-767.

Zahm, D.S. \& Heimer, L. (1993) Specificity in the efferent projections of the nucleus accumbens in the rat: comparison of the rostral pole projection patterns with those of the core and shell. J. Comp. Neurol., 327, $220-232$.

Zhang, M. \& Kelley, A.E. (2000) Enhanced intake of high-fat food following striatal mu-opioid stimulation: microinjection mapping and fos expression. Neuroscience, 99, 267-277. 